\title{
TITLE: UNDERSTANDING ENVIRONMENTAL SUSTAINABILITY AS A COMPLEX SYSTEM: USE OF AN AGENT-BASED PARTICIPATORY WATERSHED SIMULATION
}

\author{
A Dissertation \\ Presented to \\ The Faculty of the Curry School of Education \\ University of Virginia \\ In Partial Fulfillment \\ of the Requirements for the Degree \\ Doctor of Philosophy \\ by \\ Jennifer Brammer Elliott, B.A., M.Ed.
}

May 2013 
(C) Copyright by

Jennifer Brammer Elliott

All Rights Reserved

May 2013 


\section{ABSTRACT \\ Chairperson: David Feldon, Ph.D.}

Understanding the functions and properties of complex systems is necessary for participants pursuing education and careers in the areas of science, technology, engineering, and mathematics (STEM) because the fundamental constructs of complex systems apply across many domains and are at the heart of the solutions to many global issues facing the world today (National Science Foundation, 2009). Complex systems understanding has been a persistently difficult set of concepts for participants to learn and the science community, despite years of effort, has been unsuccessful in achieving complex systems understanding at the undergraduate level. There is a need for new technologies to be developed to help improve the way complex systems understanding happens and evidence that agent-based simulations can be an effective learning tool in this context. The purpose of this study was to examine complex systems understanding with the use of an agent-based simulation called the UVA Bay Game. Using a mixed methods, cross-case analysis, this exploratory study examined how undergraduate participants in three separate courses experienced changes in complex systems understanding with the use of the UVA Bay Game through the development of concept maps and written reflections on their learning. While one of the cases yielded evidence of nonsignificant quantitative change between pre and post-simulation concept maps, this study supported an overall positive increase of complex systems understanding through both concept map analysis and narrative reflections on learning. Understanding how participants experience an increase in complex systems understanding with the use of a particular agent-based simulation will help us better understand how learning happens in this context and how we best design simulations to maximize participant learning outcomes. 


\author{
Department of \\ Curriculum, Instruction, \\ and Special Education \\ Curry School of Education \\ University of Virginia \\ Charlottesville, Virginia
}

\title{
APPROVAL OF THE DISSERTATION
}

This dissertation, "Understanding Environmental Sustainability as a Complex System: Use of an Agent-Based Participatory Watershed Simulation," has been approved by the Graduate Faculty of the Curry School of Education in partial fulfillment of the requirements for the degree of Doctor of Philosophy.

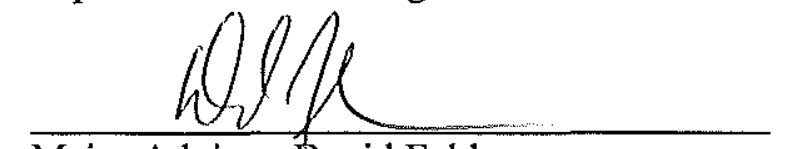

Major Advisor, David Feldon

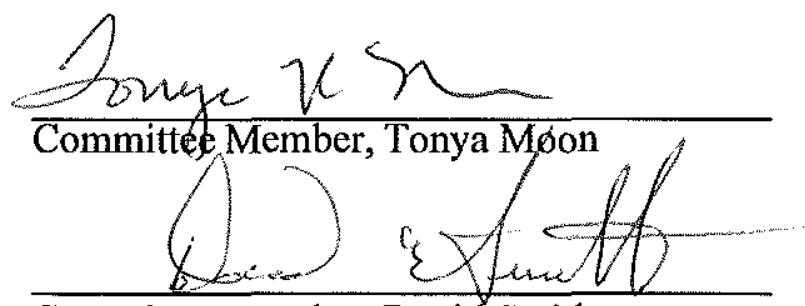

Committee Member, David Smith

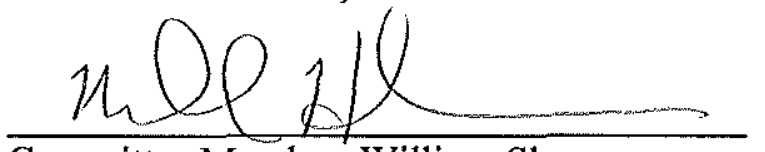

Committee Member, William Sherman 


\section{Dedication}

For my amazing family, each and every one of you. 


\section{Acknowledgements}

Completing this process has been a long journey, one that I could have never completed alone. Only one us of will graduate with a doctorate degree as a result of this endeavor, but there is an entire village that helped me earn it.

Firstly, I dedicate this book to my partner, Michael, who has endured more than any one man should in supporting my academic journey. Thank you for picking up every responsibility mentionable, from raising our child to cleaning our house to giving me solitude when I needed it. Your willingness to be a support in whatever form I needed was humbling and, for you, I am more grateful than I could possibly express. Your selflessness is but one of the many reasons my love for you grows each day.

And to my son Sam, who has been as patient and strong as a boy could be. My hope is that as you witness this process full of hard work, disappointments, achievements, happiness and sadness, you will know that, although nothing in the world comes without hard work, all good things can be yours through dedication, perseverance, and the support of those around you.

To Lauren, I thank you for your many years of love and support and your unique ability to relate, given your own simultaneous journey through graduate school. Your dedication to teaching is an inspiration and I have no doubt your influence and passion will reach students far and wide.

My gratitude to my parents and sisters cannot possibly expressed in words. They have been babysitters, chauffeurs, cooks, playmates, entertainers and every role in between. They were available without question whenever I needed to head out on my hour and half trek to The University. They have been my personal cheerleaders - everyone needs cheerleaders. For your tireless love and support I am more grateful than you will ever know. 
And for my cousin and dear friend, Jill Brammer Ware, who has provided countless hours of moral support and helped center me when balance seemed impossible, I thank you.

To David Feldon, I am most grateful for your support and hours of edits and feedback. I have learned through this process, more than I could have imagined and thank you for your guidance throughout this long journey. For taking the time to call even when the only time you had was between piano lessons or with sick children, or even with a baby on your chest, I appreciate your dedication to my success.

And to my committee members, Tonya Moon, William Sherman, and David Smith, thank you for your support, careful edits, feedback and flexibility from proposal to completion. I am grateful to have such an amazing group of scholars guiding me in my research. 


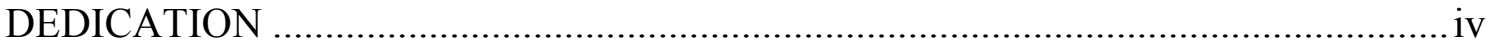

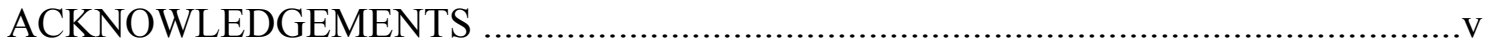

TABLE OF CONTENTS ...................................................................................... vii

LIST OF TABLES ...............................................................................................iii

LIST OF FIGURES …………............................................................................viii

\section{ELEMENTS}

I. CHAPTER 1, INTRODUCTION …………………................................ 1

II. CHAPTER 2, LITERATURE REVIEW ……………………………..... 9

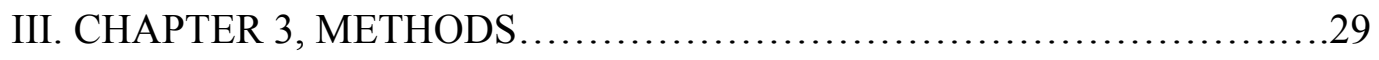

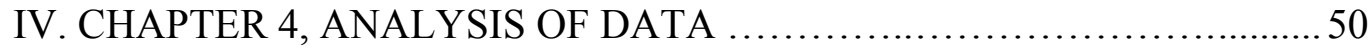

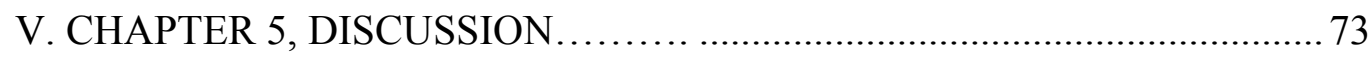

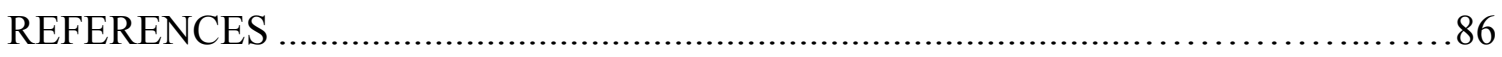

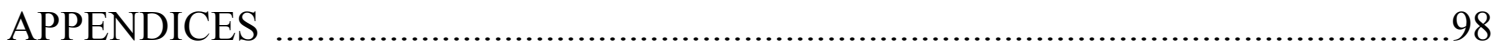




\section{LIST OF TABLES}

TABLE

Page

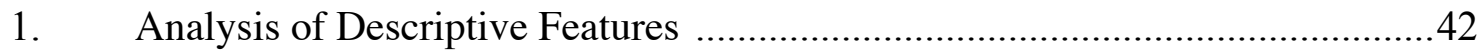

2. Comparative Analysis...........................................................................43

3. Deductive Codes Used for Qualitative Reflection Analysis...........................47

4. Data Collection Across Cases............................................................................48

5. Case 1 Outcome Measure Using Similarity Metric ........................................52

6. Case 1 Paired T-test Results for Pre/Post-Simulation Concept Maps ................55

7. Case 2 Outcome Measure Using Similarity Metric .......................................56

8. Case 2 Paired T-test Results for Pre/Post-Simulation Concept Maps ................57

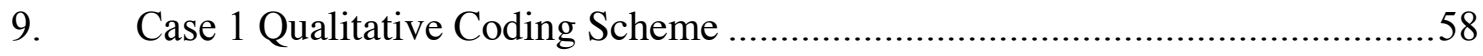

10. Case 2 Qualitative Coding Scheme ...........................................................67

11. Evidence Across Cases in Support of Findings ......................................... 75 


\section{LIST OF FIGURES}

FIGURE $\quad$ Page

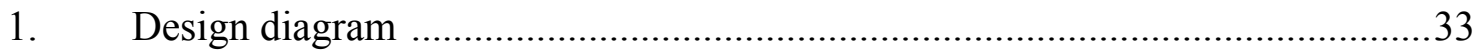

2. Participant drawn concept map before being encoded and standardized ...........40

3. AKOVIA generated representation of concept map....................................41

4. Pre- and post-simulation hand drawn concept maps ...................................46

5. Illustration of concept map pre/post structural differences. .............................54 


\section{CHAPTER 1}

\section{INTRODUCTION}

\section{Statement of the problem}

Complex systems are those with multiple levels of interaction, where linear connections between cause and effect cannot readily be established and where outcomes are emergent or exhibit self-organization (Ottino, 2004). In contrast, outcomes of simple systems can be determined a priori, regardless of the number of its parts or interactions. The individual components of simple systems can be examined and understood in isolation, and they function as wholes equal to the sums of their parts.

Understanding the functions and properties of complex systems is necessary for individuals pursuing education and careers in the areas of science, technology, engineering, and mathematics (STEM), because the fundamental constructs of complex systems apply across many domains and are at the heart of the solutions to many global issues facing the world today (National Science Foundation, 2009). For example, modeling human behaviors and their interactions with the environment requires integration of short-term human interactions and decisions with long-term environmental consequences. A recent NSF (2009) report states:

Studying the components of environmental systems in isolation from each other is no longer a meaningful approach. If we are to understand mechanisms that couple natural and human systems, we need to match the scale of observation of Earth system processes with the scale of observation of human behavior and social processes (p.17). 
Despite calls from the science community for nearly 50 years, our education system has not risen to the challenge of educating children with the kind of scientific literacy that incorporates complex systems understanding (American Association for the Advancement of Science Project 2061, 2009). Thinking about the environment as a complex system will be an imperative skill for our students, who will be charged with finding solutions to the many environmental challenges we face (Jacobson \& Wilensky, 2006). Many of these issues have been historically addressed at a local level, which is no longer sufficient (Learmonth, Plank, Sherman, White \& Smith, 2011). A broader systems perspective is a requirement for our citizenry if there are to be improvements in our environmental conditions. Advancing a systems perspective of earth systems that addresses the complex nature of human and natural interactions from the micro to the macro level is crucial.

This research focuses on an approach to teaching about a specific environmental complex system, the Chesapeake Bay watershed. Humans are increasingly stressing the natural and social systems on the planet with population increases and unprecedented global development (Chesapeake Bay Program, 2008). While the effects of human and natural systems interactions occur at a small scale, at an aggregate level those problems lead to disruptions of biodiversity and ecosystems that are collectively threatening the sustainability of the planet (Chesapeake Bay Program, 2008; NSF, 2009).

The Chesapeake Bay is one of the many systems facing serious sustainability issues. For many years, the health of the Chesapeake Bay has been declining due to factors that involve both human and natural systems. Attempts to address these issues have centered largely on local policies. Further, the watershed spans seven states, each containing many counties, with policies established and implementation determined somewhat independently in each. Most 
stakeholders, in line with most human systems, make decisions based on their personal needs and their perceptions of the state of the health of the bay (NSF, 2009).

The Chesapeake Bay is the largest estuary in the United States and its health is relevant to many, whether or not they live close to the bay. Its health is paramount in sustaining public health, economic systems, food systems, and biodiversity. The Chesapeake Bay watershed is a prime example of a complex system that has been victim to policy bandages that has lacked a systems perspective and has focused largely on local issues. Consequently, the aggregate effects of these diverse decisions cannot be modeled or predicted using a linear system model; the interactions can lead to unanticipated outcomes reflective of system complexity (Chesapeake Bay Program, 2008).

\section{Difficulty Learning in Complex, Ill-defined Domains}

Complex systems concepts are difficult for students to understand for several reasons. First, students spend most of their science studies in school working on problems for which there are known solutions (Jacobson \& Wilensky, 2006). Even when they engage in authentic inquiry activities, there is typically a charted process to follow and an expected outcome or outcomes that can be predicted (Resnick, 1996; Metz, 2008; Windschitl, Thompson, \& Braaten, 2008). Second, students who do not understand complex systems often try to intuitively explain events and processes from a perspective that attributes them to a single leader or entity when there are, in fact, multiple interacting elements (Resnick \& Wilensky, 1993). Third, students have difficulty recognizing emerging order or patterns from seeming randomness (Resnick \& Wilensky, 1993; Resnick, 1996; Wilensky \& Resnick, 1999) and understanding that actions at one level-for example, the micro level of a complex system - can have enormous impacts at another level (e.g., the macro level) (Feltovich, Coulson, \& Spiro, 2001). 


\section{Simulations for Learning}

According to Seel \& Blumschein (2009):

A simulation is a method of teaching/learning or evaluating learning of curricular content that is based on an actual situation. The simulation, designed to replicate a real-life situation as closely as desired, has participants assume roles as they analyze data, make decisions, and solve the problems inherent in the situation. As the simulation proceeds, students respond to the changes within the situation by studying the consequences of their decisions and subsequent actions and predicting future problems/solutions. During the simulation, students perform tasks that enable them to learn or have their learning evaluated. A well-designed simulation simplifies a real world system while heightening awareness of the complexity of that system. Students can participate in the simplified system and learn how the real system operates without spending the days, weeks, or years it would take to undergo this experience in the real world (p.8).

Although there is a growing body of evidence indicating that simulations, in conjunction with appropriate content instruction, are helpful for students to build complex systems understanding, the research is conflicting and varies widely (Clark, Nelson, Sengupta, \& D’Angelo, 2009). Some simulations have demonstrated positive outcomes in learning about complex domains, systems thinking, and scientific processes (Vogel et al., 2006). For example, simulations that model complex systems and allow students to engage with complex problems have demonstrated positive learning outcomes or increasing sophistication of system understanding (Yoon, 2008) in domains such as the prisoner's dilemma (e.g., Tit for Tat; Klopfer, Yoon \& Perry, 2005), the spread of epidemic disease (e.g., Virus; Klopfer, et al., 
2005), and, predator-prey relationships (e.g., Big Fish Little Fish; Klopfer et al., 2004). Some of these simulations require the students to take on a role in a system, experience a god's eye view, learn factual information about a system, or learn about the interactions of system components.

This environment can be more helpful than using static problems with known correct processes, because students are able to carry out and experience a scenario in which their misconceptions may become evident (Jacobson et al., 2006). Agent-based simulations address issues by allowing users to make decisions in a particular environment and affect the system behaviors. They give rich descriptions of player roles and advantages and constraints related to their position, background and duties within the simulation (Gredler, 1996). By making connections between the classroom and the real world and providing experience in complex systems, simulations can be advantageous for learning (Tobias, Fletcher, Dai, \& Wind, 2011).

Despite the evidence of positive outcomes in learning with simulations, the research is uneven. A recent meta-analysis (Vogel et al., 2006) described the many methodological issues related to the body of research focused on learning with simulations and identified multiple problems across the literature. The literature is inconsistent. Many studies show positive cognitive gains compared to traditional teaching methods (lecture, paper and pencil, text-based), while others do not. Issues that made the comparisons difficult included that there were multiple, common problems with both methodology and reporting. The skills to be learned varied widely, as did the ways in which the computers were used in the simulations. Additionally, many of the studies do not describe the population or apparatus well enough for studies to be replicated. Controlling for these variables, by only focusing on studies that included cognitive gains or attitudinal change as the main variables of interest, and eliminating 
research that did meet methodological standards (e.g., lacking a control group), the metaanalysis indicates that overall, students who used simulations or games experienced increased cognitive gains when measured against traditional pedagogical methods. Additionally, there is a main effect showing student attitudes toward learning were more favorable when computers were utilized as compared to traditional pedagogical methods. Importantly, we lack knowledge of what characteristics of simulations may foster learning and what cognitive constructs play a

role in this environment. Although there are many studies examining learning and simulations, the nature of the knowledge gained and the affordances that may maximize the effectiveness of learning with simulations are still not well understood (Young, Slota, Cutter, Jalette, Mullin, Mullin, Lai, Simeoni, Tran \& Yukhymenko, 2012).

Given the call to increase student understanding of complex systems, the inconsistent research on simulations and complex systems learning, and the need to better understand what characteristics may contribute to learning in this environment, the purpose of this study is to examine a particular simulation that incorporates known elements that have been successful in fostering systems learning in complex domains to determine if the simulation is associated with increased understanding of complex systems. Given that students can learn through the simulation experience by being confronted with information that may contradict their current system understanding, this research seeks to understand how learners make sense of changes in their understanding of complex systems with a particular simulation.

\section{The Present Study}

The current study builds on research that supports the use of participatory agent-based simulations as experiential tools for helping students understand complex systems (e.g., Blikstein \& Wilensky, 2005; Gredler, 2004; Jacobson \& Wilensky, 2006; National Research 
Council, 2011; Resnick \& Wilensky, 1998; Sengupta \& Wilensky, 2009; Vogel et al., 2006). These simulations allow participants to experience the complexities of the factors and interactions that contribute to the health of an endangered watershed system by becoming stakeholders who play a role at the micro-level by engaging in decision making pertinent to their livelihoods.

Simulations allow users to see a macro-view of the system that real-life stakeholders cannot. Students are privy to information across the watershed and stakeholders unavailable to real-life agents. They are able to see the results of the collective decision-making process outcomes in each round including economic and environmental consequences, giving them the ability to view the system from a holistic perspective, in addition to their individual decisionmaking viewpoints. With this perspective, students can develop mental models of the system and the interactions between their own decisions and those of the other stakeholders. Additionally, students experience how those decisions interact collectively with the environmental components of the system. While they cannot see the algorithms that model the system, the experiential nature of the simulation allows them to create a mental model of the elements and their interactions as they interpret system function. Thus, through experience they are able to view individual factors as inextricable from one another without affecting the system as a whole. This inductive sense-making occurs as students move through the simulation and changes progressively as new patterns emerge within the system (Blumschein, Hung, Jonassen, \& Strobel, 2009).

In order to further the research on complex systems learning with simulations, this study will examine the UVA Bay Game, an agent-based simulation of the Chesapeake Bay watershed system (Learmonth et al., 2011). Understanding if and how learning changes with the use of 
this particular simulation is a starting point for further research that will isolate more specific constructs in the simulation environment that affect learning. Identifying these constructs will contribute to the deliberate instructional design of simulations that can foster complex systems understanding and help students make connections across multiple systems and levels. This moves toward the end purpose of preparing participants to be effective problem solvers able to address global system challenges. The purpose of this exploratory study is to gain a better understanding of the extent to which student comprehension of salient complex system concepts may be enhanced through the use of a participatory simulation. Specifically, the following research questions were addressed:

1. Is the use of an agent-based, participatory simulation of a watershed system associated with an increase in undergraduates' understanding of system complexity?

2. How do participants describe their changing understanding of the system associated with simulation use? 


\section{CHAPTER 2}

\section{REVIEW OF THE LITERATURE}

In order to meaningfully examine the research questions in this study, it is necessary to identify distinguishing features of complex systems and describe common difficulties and misconceptions learners face when trying to understand them. The previous research evidence identifying effective elements of pedagogical practices designed to increase complex systems understanding, including the use of simulations will also be reviewed. Using situated cognition and mental model theory as a framework, this chapter describes participant problem-solving characteristics in ill-defined domains. Synthesizing the research on these converging areas and aligning that with the known effective design characteristics of the UVA Bay Game, I hypothesize that the use of this agent-based, participatory simulation will be associated with increased gains in understanding of the Chesapeake Bay as a complex system.

\section{Mental Models and Learning}

Human beings represent their understanding of the world using mental models, which are flexible knowledge structures that represent information and their interconnected relationships relevant to solving situated problems (Jonassen, Strobel, \& Gottdenker, 2005). Theories of situated cognition explain how individuals form a concept of an organized environment from their symbolic interactions within it and their perceptions of it (Seel \& Blumschein, 2000). Within this framework, learning refers to a person's ability to synthesize information, integrate it into their current knowledge, and make meaning from their environment. Learning and thinking occur as the interaction between the learner and the environment. This can be 
comprehended through a person's use of mental models that can simulate the properties and interactions in a given situation (Seel \& Blumschein, 2000).

Mental models are described as constructions in people's minds that represent imagined situations, externally experienced processes and events (Johnson-Laird, Byrne, \& Schaeken, 1992). They are used to simplify processes, visualize processes, reason a cause, or visually “walk through" a scenario (Seel, 1999). Further, they represent not only the particular elements of concepts, but also the important temporal and spatial connections between and among those elements (Jonassen, et al., 2005). According to advocates of situated cognition, in order for learning to occur in the face of problem solving or reasoning cause and effect events, mental models must be created or modified (Seel \& Blumschein, 2009).

For decades efforts have been made to understand how learning in and about complex systems occurs (Sterman, 1994). To understand how the changes to mental models, or learning, happens, we need to understand how mental models work. Johnson-Laird (1983) described key components of mental models as including structural correspondence with the concepts they represent like a visual image. However, mental models differ from mere visual images in that they provide the underlying structure upon which a person can create a concept of a system (Johnson-Laird, Girotto \& Legrenzi, 1998).

Mental model theory assumes that general existing knowledge and understanding are the blocks upon which reasoning is built, that people create models based on what they know. When they can determine that their models fit a situation, there are no changes made, but when there is a contradiction in what they know and their mental model of a situation, they may draw a different conclusion by testing its validity (Johnson-Laird, et al., 1998). In the context of our everyday lives, we are interacting and mentally manipulating our environments, taking in visual 
information, recognizing the effects of our impact on things around us, as well as, interpreting how we think objects might behave based on imagined manipulations. Further, people engage with the interpretation of their interactions and their effects on outcomes, manipulating objects to think through the consequences of their actions (Jonassen, 2006).

Mental model theory further assumes that there are limitations to working memory and that constructing models is a way to more efficiently determine truth and falsehood in situations. When learners attempt to make inferences in systems that require multiple models but they have only developed a single model, they may draw invalid conclusions. Additionally, they may not seek alternative models in determining the choice between two actions. That is, they may only carry out in their minds one possibility and neglect an alternate decision. This seems to be true when people are unaware of the opportunity-cost involved in their decisionmaking (Johnson-Laird et al., 1998).

As decisions increase in complexity and more options are available, it is more difficult to call multiple models. The limited capacity of working memory makes it difficult to juggle multiple models, and decisions are often left unmade until alternatives are reduced to no more than two, or learners experience the disjunctive effect. Johnson-Laird et al. (1998) describe the phenomenon of the disjunctive effect in an additional form, where decisions become more difficult when learners cannot infer reason behind a choice due to limited working memory capacity.

According to Shute, Jeong, Spector, Seel, \& Johnson (2009), our experiences and knowledge in the world can be conceptualized as networked concepts (nodes) and their interconnections (links). When it comes to qualitative reasoning, individuals make sense of environments when they manipulate, mentally, constructs in a system to help understand and 
solve problems. Mental models constantly evolve based on our experience and context and can often contain misconceptions or contradictory evidence (Seel, 2003). As constructs of the mind, mental models help a person make sense of complex phenomenon through restructuring and reorganization of their understanding (Shute et al., 2009).

\section{Problem-solving and Conceptual Change in Mental Models}

Situated cognition assumes that people create mental models to make sense of the world around them (Jonassen et al., 2005). In learning, we are especially interested in how people use mental models as tools for problem solving. Problem solving is a complex mental act that requires the engagement of a multitude of cognitive activities that requires learners to work at identifying what the problem is, and the process of developing a solution(s), and an acceptable solution(s) (Jonassen, 1997).

When we are trying to understand how students experience conceptual change in problem solving, accessing learners' mental models can be helpful by shedding light on how they view systems. Mental models organize the structure of concepts and elements in sense making. Learners may also reconfigure mental models when elements do not fit in an existing model or when they want to think through a possible scenario. When an event does not match an existing mental model or schema, changes in mental models can occur through the processes of accretion, tuning, and reorganization (Seel, Ifenthaler, \& Pirnay-Dummer, 2009). Accretion is when new knowledge is added to schemata that already exist. This is when the learner, who has an understanding of a particular concept, expands the concept with additional information that still fits with the existing schema. Tuning is the adjustment of single elements in an existing schema. Tuning happens when the learner has an existing schema that makes sense for a concept, but a component needs to be added, removed, or moved to adjust with new knowledge. 
Re-organization is the accommodation of finding a schema that works when accretion and tuning are insufficient or there is no schema at all. Re-organization is the most complex of these cognitive processes (Seel, 1999; Seel, et al., 2009). People experience re-organization or restructuring in the process of trying to accommodate new information through the creation of a mental model (Seel, 1999).

Experiencing change in mental models is a necessary component of learning about complex systems. However, merely experiencing a change in conceptual models does not necessarily equate to meaningful and sustained changes in learning (Jonassen, et al., 2005). Further, only experiencing a change in mental models by having someone tell about their revisions (talk aloud), results in weak and unsustained cognitive change. In order for meaningful learning to occur experiences need to go beyond the articulation of new connections and students need to engage in notable restructuring in their mental models (Jonassen, 1997).

Conceptual change in mental models of learners can be seen by making comparisons of mental models over time (Jonassen et al., 2005). And when the progression of conceptual change is elicited in externalized mental models, like concept maps, we can begin to measure learning in complex domains. Many studies have focused on the examination of concept maps as representations of mental models in well-defined problems, but these studies are limited in the insight they can provide as to the cognitive changes that happen to learners in the process (Shute, et al., 2009).

\section{Concept Mapping}

Concept mapping was first introduced as a tool for understanding science by Novak (1990). Concept maps are representations of internal cognitive schema that people use to help conceptualize problems and solutions in complex domains. These models allow learners to 
imagine a system in their head, where they can think about how their actions or decisions in a simulation might play out. In a simulation, learners may already have formed a mental model of a system, one that perhaps includes misconceptions based on centralized thinking or direct cause and effect between elements. Concept maps are tools that can elicit and externalize mental models through drawing, either by hand or with a computer program. Concept mapping, creating a model, allows the learner to identify and link events and constructs in a system as well as their interrelationships within it (Jonassen, 2005). Simulations allow learners to iteratively define and test their understanding of complex systems (Blumschein et al., 2009) and concept mapping allows them to portray external representations of those models. In consideration of the issues that face the environment rooted in the interconnectedness between human, social and ecological systems, engaging with simulations allow learners the opportunities to test their concepts. Creating and refining models of their understanding through such experiences can help a student become a better scientific thinker by engaging them in the prediction of systems outcomes and the testing of particular effects that changes made on a system may have (Jonassen, 2005). Iteratively defining and testing their mental models with a simulation and externalizing their understanding can help them better comprehend the relationships and levels of interaction within a complex system.

\section{Features of Complex Systems}

Complex systems are those that consist of many parts or elements, exhibit emergent patterns in behavior, and demonstrate adaptability (e.g., ecosystems, traffic patterns, and the spread of pandemics). Ottino (2004) makes a clear illustration of the differences between complex systems and systems that are merely complicated (sometimes referred to as clockwork systems). Ottino notes that the most complicated timepieces are referred to as trés compliqué. 
These systems entail as many as $1,000+$ parts, which must all work together for the clocks to keep time. In these systems, the collective behavior of the system can be explained by the sum of its parts. Each part has a function, and if any one part fails, the system does not have the ability to adapt. Complicated systems can include car engines or thermostats, and, as mentioned above, watches. If one component breaks, the system cannot adapt to recover (Ottino, 2004). Unique properties of complex systems include adaptability, emergent patterns that arise from decentralized loci, and varying agents that interact on multiple levels. Complex systems have parts that can be identified individually, which affect each other, and can produce outcomes or behaviors from their interactions that differ from their individual behaviors. In complex systems the interactions between individual components or elements can be more important than the components themselves, and only examining individual elements, without considering their interconnectedness will leave one with an incomplete understanding of how the system operates (Meadows \& Wright, 2008). For example, on an individual (micro) level, people in a stadium may sit and stand. However, when people follow a rule and sit and stand in reaction to the person next to them, then the macro-level result is a wave that cannot be sufficiently characterized at the micro-level.

In complex systems the interconnectedness of elements is a defining feature. When the relationships between elements in a system change, the behavior of the system changes as well, and can even make it an entirely new system. Changes in interactions can have profound effects on the behavior of a system (Meadows \& Wright, 2008).

\section{Self-organization and Decentralized Control}

Another defining feature of complex systems is self-organization, in which system elements take on the appearance of being orchestrated by a single entity. Self-organization is 
evident in many phenomena from flocks of geese, to ant food-finding patterns, to social networks.

Emergent Properties. Emergence is a hallmark of complex systems. Emergence has to do with outcomes on different levels of systems. For example, the butterfly effect is a common illustration used to demonstrate how the small movements from the wings of a butterfly can eventually result in a large weather phenomenon on another system level. There are many interactions between elements in complex systems that can happen at the same level, on multiple levels, and with varying degrees of magnitude that can result in very different outcomes at other levels. Furthermore, examining the behavior of a system at one level, may not resemble the outcomes that will emerge at another. Using the butterfly effect as an example, at the micro level, a small amount of the wind produced by the wings of the butterfly would occur, which would eventually through a series of interactions between many other elements, and across time, lead to a hurricane at the macro level. This is an extreme example, but it illustrates with clarity the large impact that small effects at one level can have on another.

Emergent outcomes across levels can be seen in a variety of situations. Elaborating on the earlier wave example, at football games people often sit and stand. This is micro level behavior that, examined in isolation, does not appear to have any significant pattern. However, when the rule at the micro level requires a person stand as another next to them sits and many people follow the rule, the result at the macro level is a wave. In addition to showing how behavior at the micro level of systems can produce an outcome at the macro level that cannot be described by the individual behavior of its elements, this is also a good example for demonstrating that the emergent phenomenon of the wave is not being organized by a "conductor" or any one entity; it has a decentralized locus of control. Only looking at people 
sitting and standing will give you a description of their micro level behavior, but it is only on the macro level that the wave is evident. Furthermore, if there are not enough people who follow the rule at the micro level, then the macro level phenomenon is not observed (Penner, 2000).

\section{Challenges and Errors in Learning About Complex Systems}

This ability to look at the world through the lens of complex systems is an important part of scientific understanding, one that is often difficult to teach. However, helping students understand how systems develop patterns of behavior, in addition to helping them see patterns and relationships at the micro and macro levels is necessary for fostering thinking that will make students effective problem solvers and arm them with the knowledge to address problems with consideration for elements of the system, their interactions, and their resultant behaviors.

\section{Ill-defined Domains and Complex Problems}

Complex problem solving can be characterized as problems in ill-defined domains or problems that lack single solutions. Funke (1991) defines complex problem solving by comparing complex systems to simple systems. Understanding the characteristics of ill-defined domains is important since problem solving is this space varies significantly from problems with a set course or charted outcomes. Funke (1991) characterized complex problems with the following criteria:

Intransparency refers to the variables in a problem that are observable to the problem solver. In simulations like the UVA Bay Game, players have limited access to the underlying structure of the system. Additionally, this criterion as described applies to this particular watershed system because there are variables that lend themselves to assessment but are so great in number that they cannot possibly all be considered, requiring the learner to select a small 
number to examine.

Polytely is the characteristic of complex problems that is defined by having multiple goals that may have conflicting interests and require compromise. This component of complex problems is characterized in this research as the roles taken on by the students, who make decisions based on their own goals, which can often be in conflict with one another. Not only may their decisions toward their own goals be in conflict with other stakeholders, but they may also conflict with larger system goals like improving the health of the bay.

Complexity of the situation is not only the idea that there are large numbers of variables in the problem, but that the number and degree of interconnections create increasing complexity that is impossible for the learner to cognitively "hold" in mind. In the Chesapeake Bay, there are thousands of variables, both human and natural, at play in the course of the simulation with enormous levels of interconnectivity.

Connectivity of variables refers to the high number of interconnections within a system that lead to the infinite possibilities in consequences. For example, making one adjustment could affect thousands of elements due to the high degree of interconnectivity. In this system, one decision made by a regulator, for example, will affect many elements in the system at multiple levels from the biological to economic.

Dynamic developments are represented by the rapid changes in a system due to positive or negative feedback loops that perpetuate certain actions, forcing the learner to make quick decisions.

Time-delayed effects demonstrate the delay between a particular action taken in a system and temporal results. In complex problems, consequences of changes may not be evident until a much later point in time. When the learners in the simulation for this research are examining 
results from round to round, they may be making adjustments that will not impact the system for many years or they make decisions in reaction to an event that is the result of a series of events that happened years ago.

\section{Common Difficulties and Misconceptions}

As described above, complex systems problems fall into a category of ill-structured or ill-defined problems, for which there may be multiple solutions or no possible solution. Not only are ill-defined problems not confined to a particular content area, they can require the consolidation of knowledge across multiple content areas to effectively comprise a solution (Jonassen, 1997). For example, developing solutions to water pollution may require a student to understand architectural development, chemical concepts, and the business of farming.

There is often a lack of a right answer, which makes teaching and learning about complex systems with traditional pedagogical approaches (lecture format) difficult, (Spiro et al., 1992). Because schools are designed with efficiency in mind, science concepts are often simplified or aggregated to a level where the complexity in their structure is no longer evident. Spiro, et. al. (1992) describe this as reductive bias. Reductive bias includes several forms like additivity bias, in which learners falsely assume that individual components that are studied apart from the system to which they belong can maintain their individual properties when examining the whole. Additionally, reductive bias includes discrete bias, in which processes (like the water cycle), which are actually continuous, are incorrectly divided into discrete steps. Lastly, compartmentalization is the oversimplification in which concepts or elements are studied without consideration for the role that their interconnectedness plays in the system. Further, when these oversimplifications are perpetual, then these misconceptions are exacerbated (Spiro, et al., 1992). 
Spiro et al. (1992) described some of the problems with failure to attain deep understanding in learning, what are deemed important concepts, without the benefits of learning how they fit into a larger picture or that their appearance and behaviors at one level may not hold true for another. Additionally, the importance of interactions between elements in systems is central to understanding systemic changes, and missing these important concepts on one level leads to misconceptions at others (Feltovich et al., 2001; Penner, 2000; Resnick, 1996; Resnick, 1997). If systems actually demonstrate complexity and we reduce them as part of our instruction, then we are making a misrepresentation of the complex system and furthering misconceptions (Spiro et al., 1992).

Science experiences in school are largely contrived demonstrations of what we know about science already and rarely have open-ended questions, or questions to which we do not have answers. Engaging students in complex thinking is an important part of learning about science. Students are learning rote steps to processes that are not reflective of the authentic behaviors in complex systems (Jacobson \& Wilensky, 2006). For example, students describe the water cycle using discrete steps or the scientific inquiry method with discrete steps. Many students' conceptions of the water cycle include having a distinct beginning and end due to their lack of understanding and interaction with cyclic concepts (Assaraf \& Orion, 2005). Teaching children that processes happen in this oversimplified and contrived manner is leading the misconception that science occurs in nature and in the world in this systematic way (Spiro, et al., 1992). There is a need to help students recognize that, while there are emergent patterns in the water cycle, it is a complex system whose interactions cannot be predicted a priori.

\section{Centralized Control}


Centralized control is a mental framework that people often use to explain many concepts in the natural world. It is the concept that some being or entity that is in control of a system. People revert to what Jacobson and Wilensky (2006) call, the deterministic centralized mindset, in which centralized control is assumed when considering how things work. However, in complex systems, behaviors are emergent and not governed by any single entity. Thus, centralized control is an insufficient explanation for system behaviors.

Centralized thinking is persistent and people often have a difficult time reconciling emergent self-organization even when they know the organizational behavior in a system cannot be explained with centralized thinking. Self-organization is often misunderstood, because it is not an intuitive concept-even for those who study complex systems (Chi, 2000; Feltovich et al., 2001; Penner, 2000; Resnick, 1996). Resnick (1997) describes an incident with Minsky, a pioneer in artificial intelligence and a systems thinker, in which Minsky notices a StarLogo simulation on Resnick's computer screen. On his computer frogs are clustering around green blobs, which Minsky assumes are a food source and wrongly assumes the frogs are organized around a central phenomenon, the food. However, in this simulation, the green blobs are actually pheromones emitted from the frogs, which build as more frogs come in proximity and stay, increasing, not only the number of frogs, but the amount of pheromones. So as each frog gathers as a result of the pheromones, the amount of pheromones increases drawing more frogs, and so on. This phenomenon is evident in other examples like ant colonies and can even be used to explain the building of social networks (Resnick \& Wilensky, 1993). Even after Minsky knows that the pheromones are the catalyst in creating an emergent pattern, he notes the persistence of centralized thinking that makes it difficult to reconcile mentally. 
This is consistent with the way most people approach problem solving (Jacobson, 2006, Resnick, 1997, Spiro et al., 1992). They assume that there is $a$ cause, which leads to the assumption that there is $a$ problem, a unique leverage point that can be traced back for $a$ single solution (causal reasoning; Spiro et al., 1992). People are uncomfortable with ambiguity and like to have linear explanations, the "right" answer (Resnick, 1997). Behaviors of complex systems defy this kind of logic, and, as Resnick (1997) pointed out, nearly everyone from novice to expert battled this urge to use centralized control to explain emergent phenomena at some point in his studies.

A study of expert and novice conceptualizations of complex systems can demonstrate this change from centralized to decentralized thinking and from emphasis on discrete, concrete system elements to abstract, unobserved interactions. Hmelo-Silver \& Pfeffer (2004) conducted a study examining middle school students' representation of an aquatic system comparing them to pre-service teachers and aquarium experts (hobbyists and biologists). This study used a structures, functions, and behaviors framework to compare the novice (students) conceptualizations of the system to the experts. When they compared the students' pictorial representation of the system (concept maps) elicited in interviews to those of experts, they found that experts were able to describe the system in terms of structures, functions and behaviors, but novice and pre-service teacher explanations were only able to articulate the structures. The experts in aquaria had a knowledge that allowed them to conceptualize the functional and behavioral components of the system that students and pre-service teachers did not.

Hmelo-Silver and Pfeffer (2004) additionally found that there were differences between professional experts (biologists) and hobbyist experts. Hobbyists described the system with a 
focus on the concrete elements in the tank itself, while biologists were able to abstractly describe the functions and behaviors of the systems from a more global or macro perspective. In addition, unlike the hobbyists who described concrete and observable processes, professional experts showed a deeper knowledge of black box processes that were not visible in the system.

\section{Promising Pedagogical Practices}

Collaborative learning, opportunities for conversations between students, and the allocation of time to reflect on the processes learners experience are helpful design strategies in developing complex systems understanding (Jacobson \& Wilensky, 2006). Knowledge is thought to be shaped by socially constructed and contextualized experiences (Brown, Collins, \& Duguid, 1989). Allowing students opportunities to give and receive feedback on their conceptualizations can be beneficial in helping them refine understanding of problems and see where issues may arise with their existing models (Jonassen, 2005). These core elements are basic instructional design components that can be implemented through many different kinds of activities (Hmelo-Silver \& Barrows, 2008; Johnson \& Johnson, 2009; Slavin, 1983). Computer environments in particular can help foster complex understanding of systems, because they incorporate multiple instructional components, which facilitate collaborative problem solving and afford students the opportunities to experience a phenomenon, reflect on the changes in their understanding, and apply new strategies to help in acquiring complex systems understanding have the potential to help systems learning (Johnson \& Johnson, 2009; Seel \& Blumschein, 2009).

Simulation as a learning tool. Simulations provide the opportunity for learners to construct their own understanding about how systems work by allowing them to explore a space, construct solutions and get feedback iteratively, from which they can determine the 
viability of their proposed solutions. Simulations allow the participant to experience interactions and behaviors in a system that they would not be able to otherwise, without spending, for example, 20 years as an actual stakeholder in a watershed. Furthermore, the simulation allows the participant to be privy to outcomes of both the results of their own actions in a system and the results of other agents' actions. In addition to experiencing the environment as part of a complex system, other affordances of simulations can include the opportunity to be part of a larger learning environment that utilizes collaborative problem solving as a necessary part of the learning experience (Johnson \& Johnson, 2009).

Simulated environments are able to provide students with feedback that allows them to iteratively react and make changes to their conceptual models as they progress through a scenario. For example, they may begin with a particular conception of the causes and effects of certain phenomenon in a system, and as a simulation progresses, they may be confronted with data that contradict their existing mental model of the system. Such feedback can lead them to adjust their thinking as they move through the simulation and reflect on why a particular choice worked or did not in any given event they experience. In addition, when students engage with simulations they are able to recognize flaws in their problem solving strategies when the system behaves in a way that conflicts with prior understanding (Gredler, 2004).

Agent-based simulations. There are many kinds of simulations and games, however the apparatus to be used in this particular study is an agent-based simulation. Some simulations are visual replicas of a situation in which the learner takes on procedural tasks, like a pilot simulation. Agent-based simulations focus on higher-level thinking and model complex dynamics (beyond procedural) (Gredler, 2004). Defining criteria are, on the simplest level, that the modeled system contains agents and is able to embody the connections between them, while 
providing the user with valuable information about the system dynamics involved, which have evolving capabilities and can demonstrate emergence (Bonabeau, 2002). In an effort to clearly define agent-based simulations Hare \& Deadman (2004) attempted to create a taxonomy of terms related to this area of study. There were five criteria they used:

1. Coupling of social and environmental models

2. Micro-level decision making

3. Social interaction

4. Intrinsic adaptation of decision making behavior

5. Population level adaptation - the search for optimal management

Simulation research that focuses on scientific understanding is well documented, but has shown mixed results. For example, Meir, Perry, Stal, Maruca and Klopfer (2005) found among college students with introductory biology experience, misconceptions in many concepts like static equilibrium, concentration versus quantity, diffusion speed and pressure are commonplace. They designed OsmoBeaker, which was intended to remedy the disconnect between observable and abstract phenomena that cannot be viewed in real life. The simulation allowed students to carry out simulated molecular experiments on osmosis and diffusion in an effort to combat stubborn misconceptions. Students were able to manipulate concentrations of molecules, walls used to test equilibrium, and the properties of the walls which would change their permeability for particular molecules. Students were pre- and post-tested on their understanding of these concepts and participants were asked to explain differences in their answers.

For some of the concepts, misconceptions were little changed as a result of the simulation, but others showed improvement. Student understanding of concepts like dynamic 
equilibrium and pressure did not improve, but complex system functions like emergence (i.e., how micro level behavior leads to self-organization at the macro level) did. Unfortunately, this study did not provide a comparison group utilizing more traditional (i.e. paper and pencil) methods, so the causal mechanisms for the change could not be isolated.

In a study by Sengupta \& Wilensky (2009), focused on investigating electric current and resistance as emergent processes from seemingly simple interactions between elements, undergraduate physics participants engaged with NetLogo Investigations in Electromagnetism (NIELS), a multi-agent computational simulation. This work focused on the misconceptions in complex electromagnetism, understanding as a slippage between levels or the explanation of phenomena from the perspective of macro-level cues without the consideration for the contributing micro-level interactions. Using NIELS to highlight the interactions between elements and levels, users interacted with the agent-based simulation to explore pre-constructed models of complex concepts in electromagnetism. Students were able to make predictions about the behavior of the model and then test their assumptions through the manipulation of variables. Through the simulation, students manipulated and tested variables demonstrating electron trajectory and charge dependence distance, in addition to concepts related to test-particles and Coulomb's Force. Students were able to observe the behaviors and interactions of elements and run the model with variable input values. This quasi-experimental design included a class of participants who all attended lectures, but, unlike the OsmoBeaker study, contained two groups, one who downloaded and used NIELS and one, assigned readings and chapter quizzes. Preand post-tests were given to assess student understanding of electromagnetic concepts in addition to follow-up interviews with a smaller group of participants to ascertain the sensemaking process participants used to describe and explain multi-level agents, interactions and 
emergent behaviors. Before engaging with the simulation $10 \%$ of students demonstrated an understanding of multi-level processes. $90 \%$ of students engaged with NIELs demonstrated understanding of micro-macro complementarity compared to $25 \%$ of the participants assigned readings and chapter quizzes. This study demonstrated the advantage of using a multi-agentbased emergent model to help students make multi-level connections in electromagnetism relative to more traditional approaches (Sengupta \& Wilensky, 2009).

Although many studies have examined a model-based approach and agent-based simulations for learning about complex systems, there is still much we do not know about how to best use these tools and the underlying cognitive principles that might be best suited to facilitate the learning of complex systems. More research is needed to help us understand how they can best be used for learning, under what circumstances they are most effective, and how we can incorporate them into curricula that can be accessed realistically by classroom teachers.

In summary, complex systems are those that pose learnability problems for students for which we have yet to come up with robust pedagogical solutions. Difficulties with complex systems concepts like decentralized control, emergence, and self-organization do not lend themselves well to traditional teaching methods that can oversimplify processes and lead to misconceptions. Mental models developed by students in an effort to problem solve in illdefined domains, tend to be linear and mechanistic and do not usually entail the conceptualization of systems on multiple levels.

New tools are needed to help students make connections and representations that aid in the understanding of complex systems. Certain pedagogical elements, like collaborative problem solving (Johnson \& Johnson, 2009), enhance a learner's ability to make iterative changes in a system and observe consequences. Time to reflect on learning is also helpful in 
fostering complex systems understanding (Jacobson \& Wilensky, 2006). Agent-based models and simulations can offer these affordances to facilitate learning in ill-defined domains.

\section{Hypothesis}

With the use of a particular simulation I hypothesize that as players engage with the simulation over time:

1. Their post-game concept maps demonstrate a decrease in similarity between their preand post concept maps, indicating change in their mental models that corresponds to increased understanding of the system.

2. Based on the literature in situated cognition, mental models, and potential pedagogical affordances of simulations for learning in complex domains, I hypothesize a change in participant understanding that demonstrates increased understanding of the complexity of the watershed system.

3. Further, it is anticipated that participants will metacognitively describe the changes in their pre- and post-simulation maps as an increased understanding of the watershed system in support of positive quantitative results. 


\section{CHAPTER 3}

\section{Methods}

The purpose of this research was to determine if use of a participatory agent-based simulation (system model) was associated with changes in complex systems understanding. Because changes in systems thinking can be effectively_but not identically-demonstrated structurally using cognitive concept maps and more holistically using narrative data, both types of data were used in this study to capture participant understanding of the watershed system (Novak \& Cañas, 2008). This mixed methods approach (Teddlie \& Tashakkori, 2009) provided data that permitted interpretive analysis of individual sense-making as well as a representation of systems knowledge in a quantifiable format to permit the measurement of change across individuals and time points.

Three discrete data sets are used for the current study. Each data set was generated through a different instance of use of the UVA Bay Game in a university course. The first offered both quantifiable and narrative data, which were collected specifically for the purposes of this study. The second case offered only quantifiable data, and the third offered only narrative data. The latter two cases were drawn from archival course data. Analyses of each case was conducted independently, and the results were compared across cases for the purposes of triangulation and replication.

\section{Participants}

Case 1. Participants in this study were 20 male and 31 female undergraduate architecture students enrolled in a Systems Architecture course at a major research university in the Southeast. Students in this course participated in the simulation as part of their regular class 
as a mechanism for understanding complex systems. Their responses were captured in the form of regular classroom assignments and assessments for the course. Because there were compatibility problems with electronic concept mapping software, participants completed their concept maps by hand (or computer) and uploaded them to the course blog page. There were originally 78 participants, however, some blogs were taken down between data collection and analysis, and other participant data were unusable, because participants did not complete either the pre- or post-simulation maps or the participant reflection.

Case 2. This existing data set was collected from an Environmental Science course, which also used the UVA Bay Game as part of it course to help students understand complex systems. Participants were 34 undergraduate Environmental Science majors enrolled at a large university in the Southeast.

Case 3. This existing data set was collected during a subsequent section of the same architectural systems course studied in Case 1. Participants were 71 undergraduates. As in the original case, participants used the simulation as part of their regular class as a mechanism for understanding complex systems.

\section{Context}

Case 1. The architectural systems course focused on the interconnectedness between scientific knowledge, technological innovation, social constructs, and cultural expression that influence the design of buildings and communities. The course emphasized large-scale interconnectivity between environmental forces, physical, multi-scale, and subjective dynamics and the examination of them for the purpose of conjuring ways to ensure the vitality of the ecosystem. Complex system behaviors and ecosystem understanding served as a foundational core to this course, which further explored the human behavioral and ecosystem dynamics as 
they related to spatial construction and the interplay of energy, heat, air, light and water. The course was intended to present students with ill-defined problems in order to cultivate habits of mind that that could help them think differently to become complex problem solvers (Course Syllabus).

The course used multiple methods of instruction, including whole group lecture and small group break out discussions with teaching assistants weekly. Participants played the UVA Bay Game as a whole group two times over a period of two weeks in a lecture hall using laptops. Initially, they were to play two times in one week, but due to a bug in the program, the second game play happened exactly one week later than the first. Participants were given information on their roles prior to game play to familiarize themselves with stakeholders they would be playing.

Case 2. This data set was collected as part of an environmental science course, Marine Environments and Organisms, in which participants played the UVA Bay Game in two sittings as part of their regular class activity over a period of one week. Participants in this course were given instruction on estuaries and the Chesapeake Bay prior to producing their first concept maps. Participants in this course were provided with additional instruction on the creation of concept maps and were provided with a standard bank of terminology for complex systems, which allowed for a more uniform collection of concept maps.

Case 3. The context for this case was identical to the context in Case 1. As a subsequent section of the architectural systems course studied in Case 1, participants experienced game play in the context of their regular course activities and played the UVA Bay Game as a whole group. As in Case 1, in addition to whole group lecture and game play, participants in this case also took part in smaller group break out discussion lead by teaching assistants each week. 


\section{Design}

This research utilized an exploratory, sequential mixed methods design (Creswell \& Plano Clark, 2007) with non-experimental, pre/post comparisons. Qualitative data were collected in two forms:

1. Pre- and post-simulation participant-created concept maps

2. Post-simulation reflections on differences in their pre- and post-simulation concept maps and descriptions of their understanding of the complex system before and after engagement with the simulation.

Following data collection, concept maps were encoded quantitatively for the purpose of statistically assessing the extent of change between time points using similarity metrics. Prepost concept map pairs were also rated by content experts to determine the quality of the measured changes. Participant reflections on the changes in their understanding were analyzed qualitatively looking for emergent themes that demonstrated an increased understanding of complex systems concepts like emergence and interconnectedness across individuals' descriptions. See Figure 1 for an overview of the research design. 


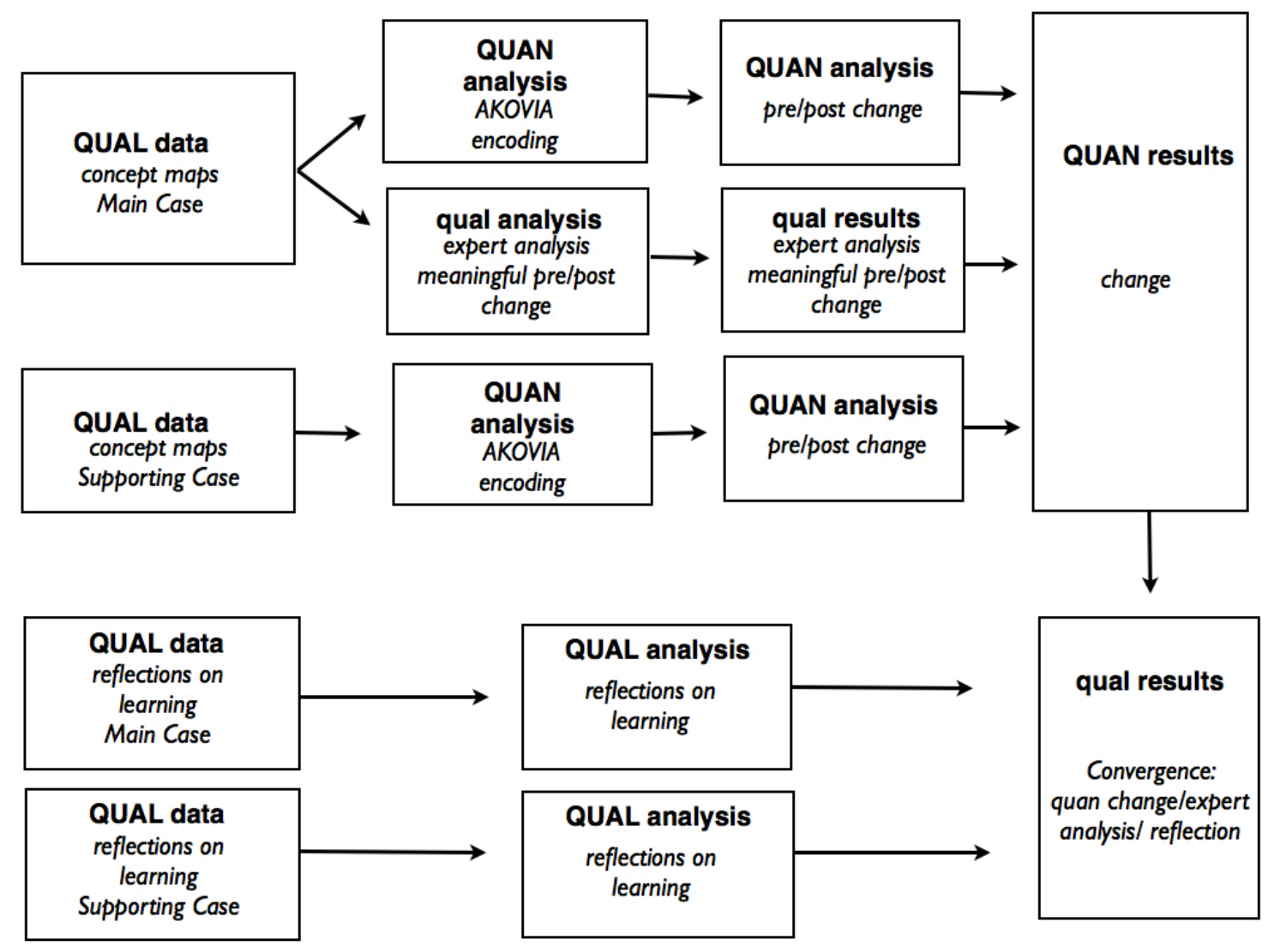

Figure 1. Design Diagram

\section{Operational Definitions of Key Variables}

\section{Complex Systems Understanding}

A change in complex system understanding in this study was the main variable of interest. Complex system understanding is a learner's ability to comprehend the role of multiple elements and their interactions across levels, as well as, the effects of emergence on a system. Participant understanding of the complexity of the watershed system was represented by mental models that participants used to conceptualize the problem space. At each time point, participants externalized these models using concept maps of the watershed system.

Concept Maps. In concept maps, complex systems understanding is operationalized through the explicit representation of participants' mental models using diagrams drawn at two 
points in time. Concept maps are comprised of nodes (i.e., concepts) and links (i.e., interconnections) representing elements and their connections in a system (Shute, 2009). Change in understanding over time is reflected in changing relationships among concept map elements, with increasing complexity of represented interactions between system elements typically indicating deeper understanding.

Personal Reflections. Personal reflections on learning and accompanying explanations of changes in the concept maps in written narrative format presented another operationalization of complex systems understanding. Capturing participant understanding can be better understood with the use of personal narratives that allow participants to reflect on how they perceived the differences in both their understanding of the watershed as a complex system and how they expressed those differences in their concept maps.

\section{Apparatus}

\section{The UVA Bay Game}

The simulation used in this study was the UVA Bay Game. It is a large-scale mathematical model of the Chesapeake Bay watershed system and models data from environmental agencies gathered between the years 2000 and 2008. The simulation models the elements in the system and their interactions across seven watersheds. Taking on the role of watermen, farmers, policymakers and developers, participants engaged in decision-making processes regarding the role to which they were assigned in an effort to balance economic and environmental sustainability. The UVA Bay Game provides an immersive learning experience in which participants take on the roles of stakeholders and experience the impact of not only, their own decisions, but also those of the other stakeholders. 
Built with STELLA® iThink v.9.1.2 modeling software (http://www.iseesystems.com/ softwares/Education/StellaSoftware.aspx), the UVA Bay Game is an agent-based simulation that models the Chesapeake Bay watershed system. The agents and elements of the systems are mathematically defined with attributes that change based on underlying mathematical models simulating interactions between elements in the environment (Richmond \& Peterson, 2001; Seel \& Blumschein, 2009). Within the game, the region is divided into seven watersheds and the North and South regions. In each watershed there are agricultural (land and animal), fishing, development, and public sectors. Farms are modeled in proportion to the actual number of farms (approximately 64,000) in the watershed and include the acres in production. Additionally, development in the simulation represents the number of urban/residential acres that will be transformed form farmland or wooded area to developments. Additionally fisheries are modeled to scale (5000). Using a "serious game" interface developed with Forio Broadcast Enterprise ${ }^{\mathrm{TM}}$, the simulation models the actions of 17 million persons and maintains behavioral fidelity to the system. This is an important aspect of the UVA Bay Game because one problem with many models in education is the fact that they aggregate elements, interactions, and behaviors to such a level that the system is oversimplified, making it difficult for students to see the complexity in the system.

In the UVA Bay Game players are assigned a role (Waterman, Farmer, Developer, Regulator) in one of seven watersheds (Susquehanna, Patuxent, James, Potomac, Eastern Shore, York and Rappahannock). The roles require the participants to make decisions about their livelihoods, which be will next described in detail.

Farmers. Within the game there are two kinds of farmers, crop farmers (Appendix A) and animal farmers (Appendix B). Crop farmers are charged with making decisions about their 
farming methods, selecting High Yield (maximum yield per acre, two choices of Best Management Practices (BMP; maximizing yield with BMP), or low-input sustainable (polyculture crops). Additionally, they will select a percentage of land to leave fallow (cropland kept out of production) and a percentage to which to apply cover crops (crops that improve conditions associated with sustainable growth). Animal farmers must choose between conventional and sustainable methods, and basic or covered storage waste treatment (manure is enclosed in container and not sold for fertilizer). If animal farmers choose covered storage, then they have the option to select nutrient removal (manure stored in covered containers, nutrients removed and sold for fertilizer).

Developers: Land developers (Appendix C) are making decisions in the game about how much land to buy and whether or not to purchase greenfield (previously undeveloped land) or infill (previously developed land that can be redeveloped). Additionally, they must decide how many acres to develop traditionally or sustainably. Further, after the first round they have the option to sell greenfield or infill acres. Development takes time, however, and when developers purchase land, it is not immediately available for sale. Developers have restrictions on their spending, which stipulate that their total spending in each round may not exceed $5 x$ their total equity, which is shown in their balance sheet after each round.

Watermen: The watermen (Appendix D) make decisions about the percentage of the open season they will dredge and pot for crabs. In addition they can purchase a new boat, which after two years (one round) will increase their dredging and potting yields by ten percent.

Bay regulator: The Bay regulator (Appendix E) determines how many crabs watermen can catch each year and controls the opening and closing of the dredging and potting seasons. 
Agricultural regulator: The agricultural regulator (Appendix F) has a significant number of decisions to make in the game. The regulator determines the subsidies and taxes that will be implemented for crop and animal farmers based on the methods farming, fallow land, and waster removal they choose.

Land use regulator: The land use regulators (Appendix F) determine subsidies, taxes, and penalties for development of greenfield or infill acreage.

Life satisfaction scores: All players in the game are responsible for ranking the overall importance to them of the economy, the environment and quality of life (100\% total) in the beginning of the simulation. After each round, players enter assessment of the health of the bay, the environment, and quality of life on a scale of $0-10$ with 0 being poor and 10 being perfect. This feedback is available to policy makers who can use it to help determine how constituents are viewing their policy decisions.

Game play. In the context of the UVA Bay Game, participants discover how their actions impact the system through rounds that require them to provide input that affects the system. For example, a farmer may choose to produce all organic crops, which will have outcomes that affect his profits, the health of the bay and the overall economy. After receiving feedback following each round, the participant then considers whether his decisions from the last round are optimizing his own goals and those for the system, and adjusts accordingly. One important feature of this simulation is allowing the participants to make decisions, have discussions during and after decision-making, and adjust decisions based on feedback.

During each round, stakeholders enter their decisions. After all decisions have been submitted, the simulation is advanced, modeling a two-year period and stakeholder decisions are carried out in the model of the watershed system. After each round players see the results of 
all decisions by watershed (Appendix H). Participants see graphic and text results of the health of the bay, the economic standings and player satisfaction with quality of life. While participants try to balance making a sustainable living, they are also trying to keep the bay healthy and meet their own projections for quality of life based on their own decisions entered in round one. Regulators use the quality of life feedback to adjust subsidies and taxes throughout the game.

Watersheds are in "competition" with one another to reach maximum economic success while balancing the health of the bay and life satisfaction. However, the goal of the simulation is designed in such a way that if any watershed fails, then none have succeeded, since the health of the bay depends on cooperation among stakeholders, not only within watersheds, but also across watersheds. This design is an important factor in the learning participants experience. It is meant to demonstrate that the problem of the failing health of the Chesapeake Bay is one that cannot be addressed by sole groups, sole states, or sole watersheds. Through engaging with the simulation, participants can experience this macro level perspective that might not otherwise be visible to them.

\section{Procedure}

\section{Data Collection}

Case one. During the data collection phase and before interacting with the simulation, participants were given instructions by their professor to respond online (Appendix I) to the following prompt, "List the variables and concepts that you think are part of the Chesapeake Bay watershed system (You can list as many as you would like. Use additional space if needed)." This prompt is to elicit the participants' pre-simulation understanding of the system. Participants were asked to complete the concept map along with the prompt, "Describe the 
relationship and interaction between these variables. Be specific. For example, if you state that A influences B, indicate the direction and nature of the influence (i.e., A transforms B in this way, A increases/decreases B, etc.).” Participant maps were created outside of class and uploaded to their (individual) class blog (electronic archive). Following interaction with the simulation participants were prompted to create follow up concept maps of the watershed system (Appendix J).

Case 2. In this case, participant developed pre- and post-simulation concept maps were collected from existing data set from an environmental science course studying complex systems. The concept maps underwent the same encoding and analysis procedure as described in Case 1. This case was used to replicate the quantitative concept map findings from Case 1.

Case 3. This data set was an existing set collected from a subsequent offering of the undergraduate architectural systems course in Case 1. The data studied for this research only focused on the participant reflections in the post game follow-up from this particular data set. These reflections were intended to provide triangulation and replication for the reflection findings in the original data set. Participants in this section responded to a prompt outside of class and uploaded their responses to the electronic archive. Participants responded the following question as part of their assignment (Appendix K), "In a short paragraph, describe an experience that you had during the game play that led to a new insight about the system or a deeper understanding of the processes at work."

\section{Data Analysis}

As represented in Figure 1, concept map data were converted from hand-drawn maps (see Figure 2) into computerized maps by creating a spreadsheet containing all of the propositions (node-link-node) for each pre- and post-simulation map. AKOVIA (Automated 
KnOwledge VIsualization and Assessment; Pirnay-Dummer et al., 2010) software then generated standardized concept maps (see Figure 3) for each participant and generated similarity metrics to determine the magnitude of changes from pre- to post-intervention concept maps.

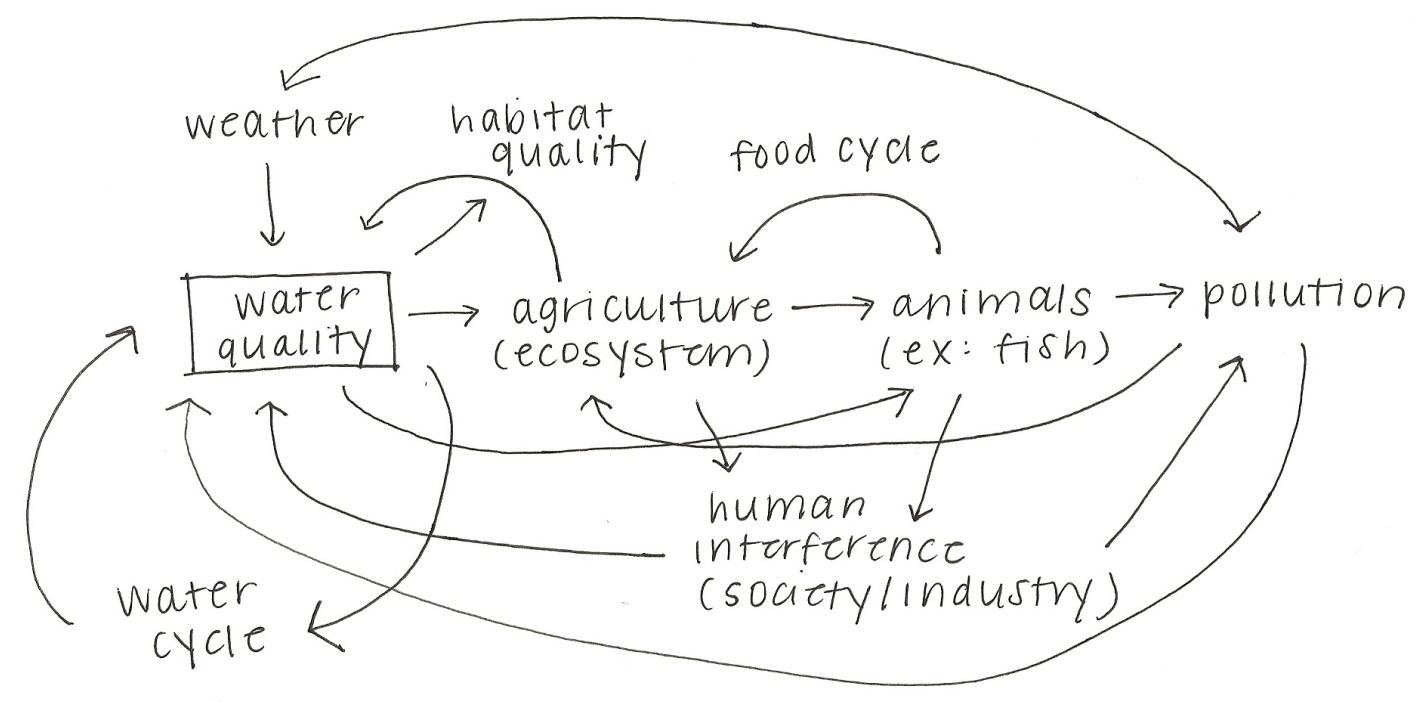

Figure 2. Participant drawn concept map before being encoded and standardized 


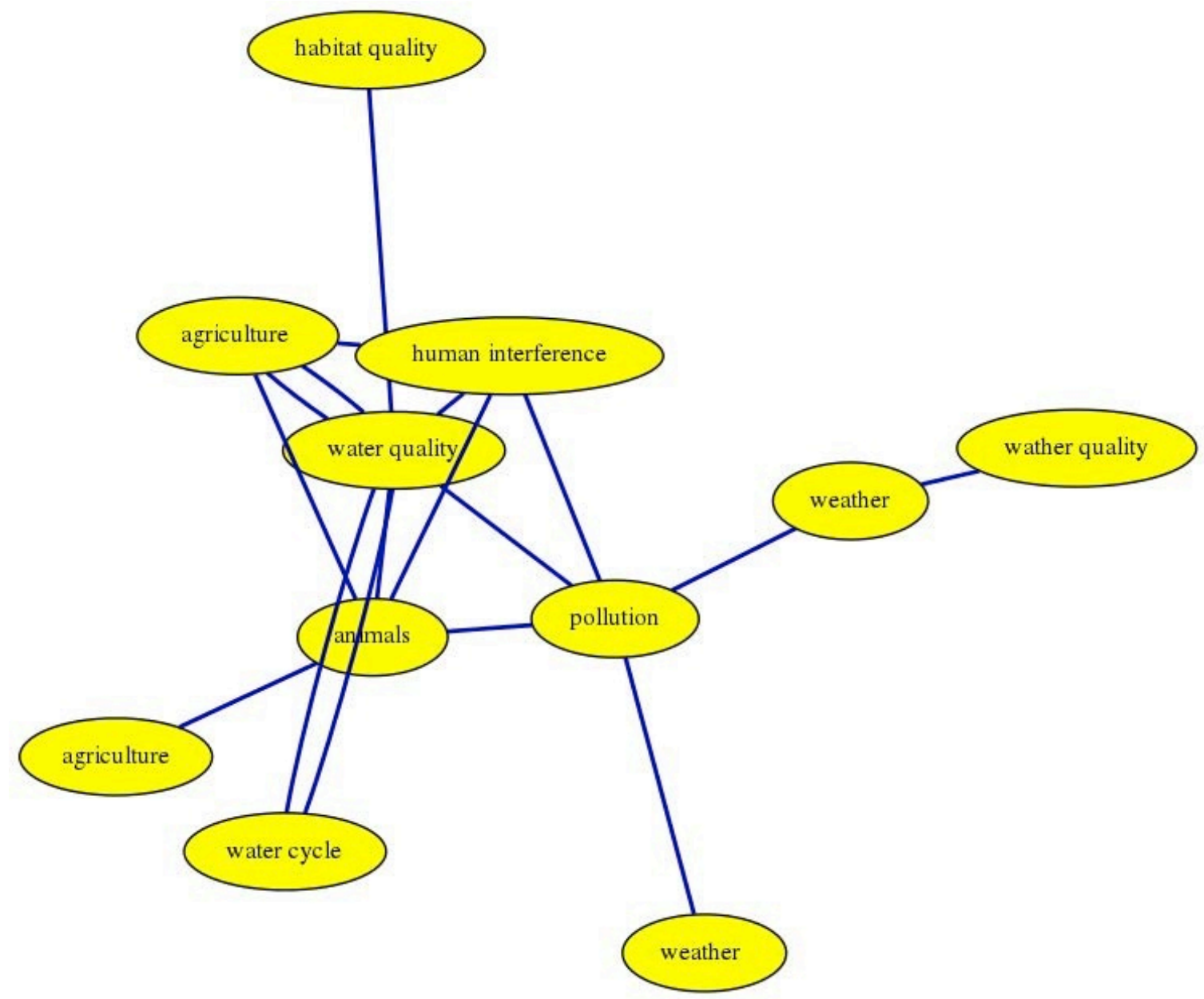

Figure 3. AKOVIA generated representation of concept map

\section{Quantitative Analyses}

AKOVIA is a SMD (surface, matching, deep) technology that is able to analyze the graphic representations to gain an understanding of how participants learn across time in complex domains, based on mental models and graph theory (see Table 1) (Ifenthaler, 2010a). Change in complexity of participant models was analyzed by assessing the number of elements included in their concept maps, the distance and quality (strength) of the relationships between nodes, and the similarity between the participants' original model and their comparison models. The resultant relationships were then represented graphically, in addition to the nodes and links that were only present in the post-game diagrams (Ifenthaler, 2010b). The analysis provided a 
bridge between the qualitative and quantitative data that helped the researcher understand the changes in processes of learning in complex domains (Pirnay-Dummer et al., 2010).

Table 1

Analysis of Descriptive Features (Pirnay-Dummer et al., 2010)

\begin{tabular}{|c|c|}
\hline Connectedness (SMD). & $\begin{array}{l}\text { Computed as the possibility to reach every } \\
\text { node from every other node in the knowledge } \\
\text { representation (cf. Ifenthaler et al., 2008). }\end{array}$ \\
\hline Ruggedness (SMD) & $\begin{array}{l}\text { Computed as the sum of subgraphs, which are } \\
\text { independent or not linked (cf. Ifenthaler et al., } \\
\text { 2008). }\end{array}$ \\
\hline Average degree of Vertices (SMD) & $\begin{array}{l}\text { Computed as the average degree of all } \\
\text { incoming and outgoing edges of the } \\
\text { knowledge representation (cf. Ifenthaler et al., } \\
\text { 2008). }\end{array}$ \\
\hline Number of Cycles (SMD) & $\begin{array}{l}\text { Computed as the sum of all cycles (a path } \\
\text { returning back to the start node of the starting } \\
\text { link) within a knowledge representation (cf. } \\
\text { Ifenthaler et al., 2008). }\end{array}$ \\
\hline Vertices / Nodes (SMD) & $\begin{array}{l}\text { Computed as the sum of all nodes within a } \\
\text { knowledge representation (cf. Ifenthaler et al., } \\
\text { 2008). }\end{array}$ \\
\hline Edges / Links (SMD) & $\begin{array}{l}\text { Computed as the sum of all links within a } \\
\text { knowledge representation (cf. Ifenthaler et al., } \\
\text { 2008). }\end{array}$ \\
\hline
\end{tabular}

The program first created a descriptive analysis of the data at each point in collection, the preand post-game concept maps. The researcher used the output to make comparisons between the two time points, as well as, across participants as individuals and groups. If there were groups within the sample who had statistically different changes or lack of change in their understanding, it may help us better understand where the game might be improved or where it has strength in helping complex system understanding.

Comparison features were analyzed by calculating the differences between models on surface structure, graphical matching, concept matching, density of vertices, structural 
matching, and propositional matching (Pirnay-Dummer et al., 2010) (see Table 2). Similarity between feature frequencies is calculated with the following:

$$
s=1-\frac{\left|f_{1}-f_{2}\right|}{\max \left(f_{1}, f_{2}\right)}
$$

The results are presented with a measure where $0 \leq \mathrm{s} \leq 1 . s=0$ demonstrates no similarity in comparison data and where $s=1$ demonstrates exact similarity or no change.

Table 2

Comparative Analysis (Pirnay-Dummer et al., 2010)

\begin{tabular}{|l|l|}
\hline Surface Matching (SFM) & $\begin{array}{l}\text { The surface measure (cf. Ifenthaler, 2006) } \\
\text { compares the number of vertices within two } \\
\text { graphs. It is a simple and easy way to calculate } \\
\text { values for surface complexity. }\end{array}$ \\
\hline Graphical Matching (GRM) & $\begin{array}{l}\text { The graphical matching (cf. Ifenthaler, 2006) } \\
\text { compares the diameters of the spanning trees } \\
\text { of the graphs, which is an indicator for the } \\
\text { range of conceptual knowledge. It corresponds } \\
\text { with structural matching, as it is also a } \\
\text { measure for complexity only. }\end{array}$ \\
\hline Concept Matching (CCM) & $\begin{array}{l}\text { Concept matching (cf. Pirnay-Dummer, 2006) } \\
\text { compares the sets of concepts (vertices) within } \\
\text { a graph to determine the use of terms. This } \\
\text { measure is especially important for different } \\
\text { groups which operate in the same domain (e.g. } \\
\text { using the same textbook). It determines } \\
\text { differences in language use between the } \\
\text { models. }\end{array}$ \\
\hline Gamma Matching (GAM) & $\begin{array}{l}\text { The density of vertices (cf. Pirnay-Dummer, } \\
\text { 2006) describes the quotient of terms per } \\
\text { vertex within a graph. Since both graphs, } \\
\text { which connect every term with each other } \\
\text { term (everything with everything) and graphs, } \\
\text { which only connect pairs of terms can be } \\
\text { considered weak models, a medium density is } \\
\text { expected for most good working models. }\end{array}$ \\
\hline
\end{tabular}




\begin{tabular}{|l|l|}
\hline Structural Matching (STM) & $\begin{array}{l}\text { The structural matching (cf. Pirnay-Dummer, } \\
\text { 2006) compares the complete structures of two } \\
\text { graphs without regard to their content. This } \\
\text { measure is necessary for all hypotheses, which } \\
\text { make assumptions about general features of } \\
\text { structure (e.g. assumptions which state that } \\
\text { expert knowledge is structured differently } \\
\text { from novice knowledge). }\end{array}$ \\
\hline Propositional Matching (PPM) & $\begin{array}{l}\text { The propositional matching (cf. Ifenthaler, } \\
\text { 2006) value compares only fully identical } \\
\text { propositions between two graphs. It is a good } \\
\text { measure for quantifying semantic similarity } \\
\text { between two graphs. }\end{array}$ \\
\hline
\end{tabular}

\section{Rating of Map Quality by Experts}

To complement the differences in concept map structure and provide qualitative assessment of conceptual improvement, two experts in environmental complex systems examined the coded pre/post concept maps in a blind review for each participant in the first data set presented via Qualtrics ${ }^{\circledR}$ electronic survey system (Appendix L). The sequence of presentation of the maps was randomly assigned for each pair, so that reviewers had an equal chance of viewing a pre- or post-concept map first when the pair was presented. Experts determine the quality of maps using possible evaluations: first map of better quality, second map of better quality, or both maps of equal quality (Figure 4). 

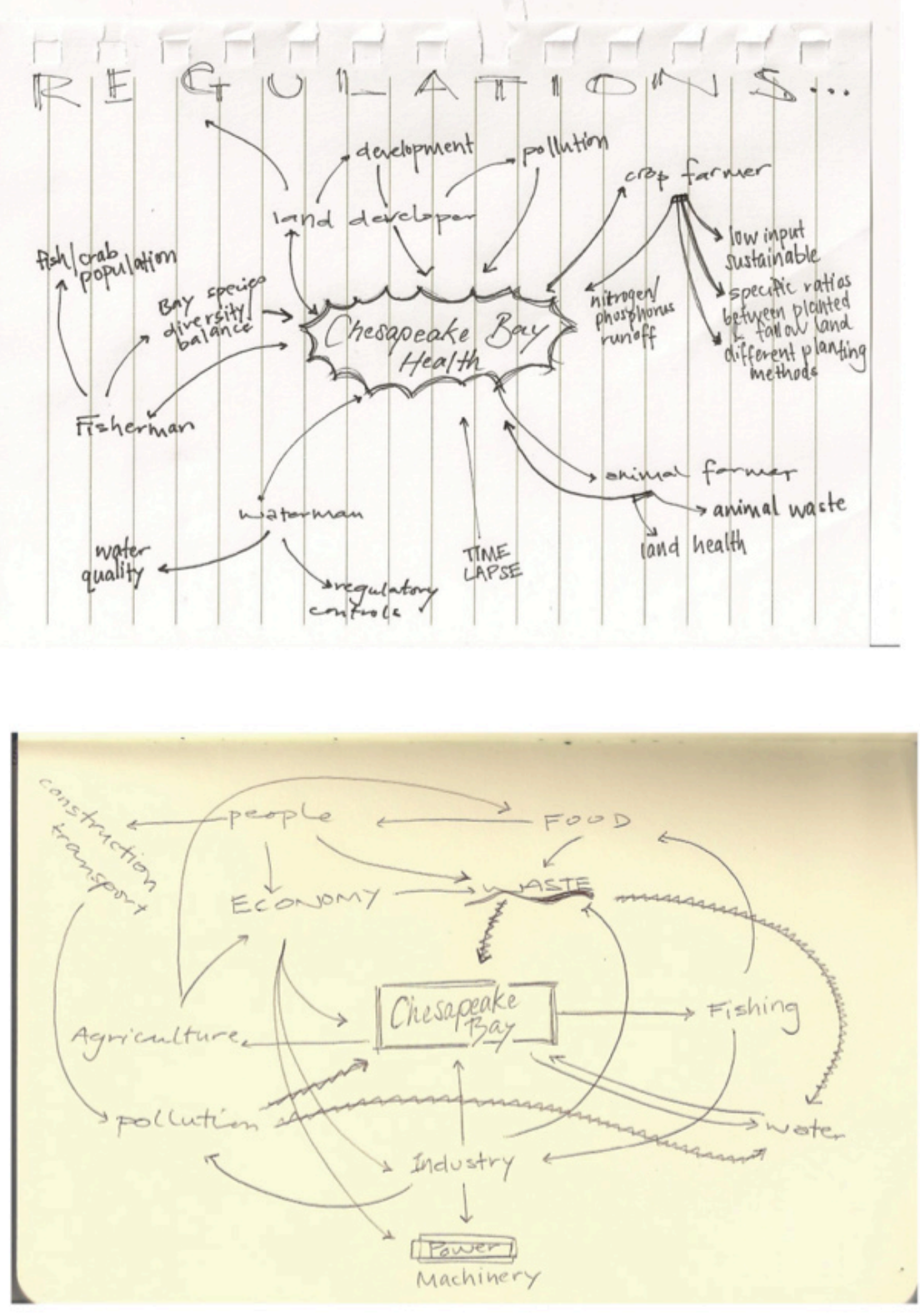
"\#1 (top) Better
" \#2 (bottom) Better
1) Same

Figure 4. An example of a pair of pre- and post-simulation hand drawn concept maps presented for expert analysis through online survey software. 
Raters made decisions on the basis of which map in the pair presented the best representation of complex systems concepts, like emergence, interconnectedness, and decentralized control, evidenced by increased connections, interconnections in maps. Experts were advised to look for evidence of understanding of these concepts that have been historically difficult to capture. Analysis of inter-rater reliability indicated a high level of agreement between the two experts' quality rating of the maps (Cohen's kappa $=0.811, \mathrm{p}<.001)$.

\section{Qualitative Analyses of Personal Narratives}

The qualitative analysis of post-game reflections of participant understanding of the watershed system before and after the simulation initially used an open coding format looking for general patterns or themes in participant perspectives (Creswell, 2007). Subsequent rounds of coding identify words and phrases in participant responses that helped to better illustrate how participants metacognitively viewed the process of learning between two time points.

Codes to represent changes in understanding were developed using inductive and deductive methods, looking for evidence of complex systems understanding based on the literature in learning about complex systems, while also coding for emergent themes that were not determined a priori. Codes were grouped and redundancy accounted for as the process was repeated until a smaller number of themes emerge from the data (Creswell, 2007). This study employed deductive data analysis with a priori themes based on the existing literature on complex systems learning, specifically, elements that are unique to complex systems learning like decentralized control, interconnectedness, emergence, etc. (Table 3). While searching for evidence of complex systems understanding the researcher also explored themes that emerged from the data, like human impact and system oversimplification or reductive bias. The qualitative data for each separate case were analyzed using a constant comparative analysis 
(Lincoln \& Guba, 1985) simultaneously coding and analyzing the data to compare occurrences of both emergent and deductively arrived themes.

Table 3

Deductive Codes Used for Qualitative Reflection Analysis

\section{Codes}

Accretion

Adaptability

Decentralized control

Delay

Deterministic Centralized Mindset

Disjunctive effect

Emergence

Human Impact

Interconnectedness

Linear Causation

Macro to Micro

Micro to Macro

Misconceptions

Multilevel Understanding

Multiple Causal Sources

Oversimplification

Pre Post Change

Reductive Bias

Re-organization

Self-organization

Tuning

\section{Integration of Quantitative and Qualitative Analyses}

The quantitative change measures across the pre- and post-concept maps provided a simple but incomplete understanding of how the simulation may or may not lead to increased understanding of complex systems. It allowed the researcher to determine if there were changes, but it could not accurately determine the quality of those changes. Using the analyses from experts on each set of concept maps, the researcher was able to objectively determine if those changes were corroborated by the experts, along with the additional qualitative analysis of the direction and quality of those changes. For example, if a pair of concept maps showed change 
from pre to post on a similarity metric, the expert analysis could then say which (if either) of the concept maps demonstrated a deeper understanding of the system. This additional information permitted the inference of change quality in addition to magnitude. Identifying emergent themes in participant reflections helped triangulate the quantitative results and used the participants' own words as a way of corroborating the interpretation of pre- and post-game concept map analyses. The coding and analysis of participants' descriptions of their metacognitive experience served as an additional triangulation component to support the quantitative concept map and expert analyses. Examining additional cases that included an additional pre- and postconcept map quantitative analysis and an additional case of participant post-simulation reflections provided additional triangulation to help provide confidence in the researcher's interpretations from the original data set (Table 4).

Table 4

Data Collection Across Cases

\begin{tabular}{|c|c|c|}
\hline Case 1 & Case 2 & Case 3 \\
\hline $\begin{array}{c}\text { Changes in complex systems } \\
\text { understanding quantitative } \\
\text { measures }\end{array}$ & $\begin{array}{c}\text { Changes in learning } \\
\text { outcomes with quantitative } \\
\text { measures } \\
\text { (replication) }\end{array}$ & \\
\hline $\begin{array}{c}\text { Change quality and direction } \\
\text { determined through expert } \\
\text { ratings }\end{array}$ & & \\
\hline $\begin{array}{c}\text { Evidence of increased } \\
\text { understanding of complex } \\
\text { systems through written } \\
\text { participant narrative }\end{array}$ & & $\begin{array}{c}\text { Evidence of increased } \\
\text { understanding of complex } \\
\text { systems through written } \\
\text { participant narrative } \\
\text { (replication) }\end{array}$ \\
\hline
\end{tabular}


This triangulation helped the researcher understand if the changes evidenced in the quantitative data were experienced by participants as increased understanding. The identification of convergence across multiple sources of data permitted a more complete understanding of how the simulation may contribute to complex systems understanding. 


\section{CHAPTER 4}

\section{RESULTS}

To answer the set of research questions posed in this study, analyses included the examination of participant-generated pre- and post-simulation concept maps, experts' comparative ratings of concept map quality, and narrative participant reflections on their learning. The following chapter reports the results of all analyses: the quantitative measure of change between pre- and post-simulation concept maps (Case 1 and Case 2), the qualitative analysis of pre- and post-simulation concept maps by experts to determine if change was meaningful (Case 1), and the qualitative narrative analysis of participant reflections on changes in their understanding (Case 1 and Case 3). The convergence of these analyses helped answer the questions posed in this research:

1. Is the use of an agent-based, participatory simulation of a watershed system associated with an increase in undergraduates' understanding of system complexity?

2. How do participants describe their changing understanding of the system associated with simulation use?

Following the data collection and encoding as described in Chapter 3, the first quantitative analysis was conducted using AKOVIA software to measure the similarity between pre- and post-simulation maps (change measure). Initial quantitative results were important as indicators of change between pre- and post-simulation chance. Using IBM Statistical Package for Social Sciences ${ }^{\mathrm{TM}}$ (SPSS), further analyses of the data determined statistical significance. 
The first section presents the results of the AKOVIA analysis, the paired t-tests across concept map criteria used to determine the statistical significance of changes between pre- and postsimulation maps, and estimates of effect size for both Case 1 and Case 2. The second section reports the qualitative expert analysis of the concept maps from Case 1. The third section includes the results of the qualitative analyses of written participant reflections on changes in their learning and explanations of the differences between their pre- and post-simulation concept maps from Case 1 and Case 3.

\section{Quantitative Analysis: Case 1}

Comparative results of individual pre- and post-concept maps from the AKOVIA software indicated that differences between pre- and post-concept maps in the first data set yielded a mean similarity metric of $.604(\mathrm{SD}=.242)$ on the Surface Matching (SFM) component. This metric reflects the proportion of concept map nodes present in both the pre- and postconcept maps between 0 (no overlap) and 1 (complete overlap). Additionally, pre- and postsimulation concept maps showed differences in span of their knowledge representations, Graphical Matching (GRM) (M=.685, $\mathrm{SD}=.163)$, the number of concepts between maps, Concept Matching $(\mathrm{CCM})(\mathrm{M}=.590, \mathrm{SD}=.257)$, the density of vertices, Gamma Matching (GAM) $(\mathrm{M}=.143, \mathrm{SD}=.238)$, and the overall structure of the concept maps without regard to content, Structural Matching (STM) (M=.065, SD=.208). Additionally, changes were reported in the semantic similarity, Propositional Matching (PPM) between pre- and post-concepts maps as well $(\mathrm{M}=.104, \mathrm{SD}=.251)$ (Table 5). 
Table 5

Outcome Measure Using Similarity Metric Where 0=No Likeness Between Maps and I=Identical Maps or No Change.

\begin{tabular}{lccccc}
\hline & $\mathrm{N}$ & Minimum Maximum & Mean & Std. Deviation \\
\hline Surface Matching (SFM) & 51 & .171 & 1.000 & .604 & .242 \\
Graphical Matching (GRM) & 51 & .333 & 1.000 & .685 & .163 \\
Concept Matching (CCM) & 51 & .000 & 1.000 & .590 & .257 \\
Gamma Matching (GAM) & 51 & -1.294 & 1.000 & .143 & .238 \\
Structural Matching (STM) & 51 & .000 & 1.000 & .065 & .208 \\
Propositional Matching (PPM) & 51 & .000 & 1.000 & .103 & .250 \\
\end{tabular}

In addition to the changes evidenced in the statistical analysis, AKOVIA also provides a standardized graphical output that makes change visually accessible. An example of a matched pre- and post-concept map are shown in Figure 5. 

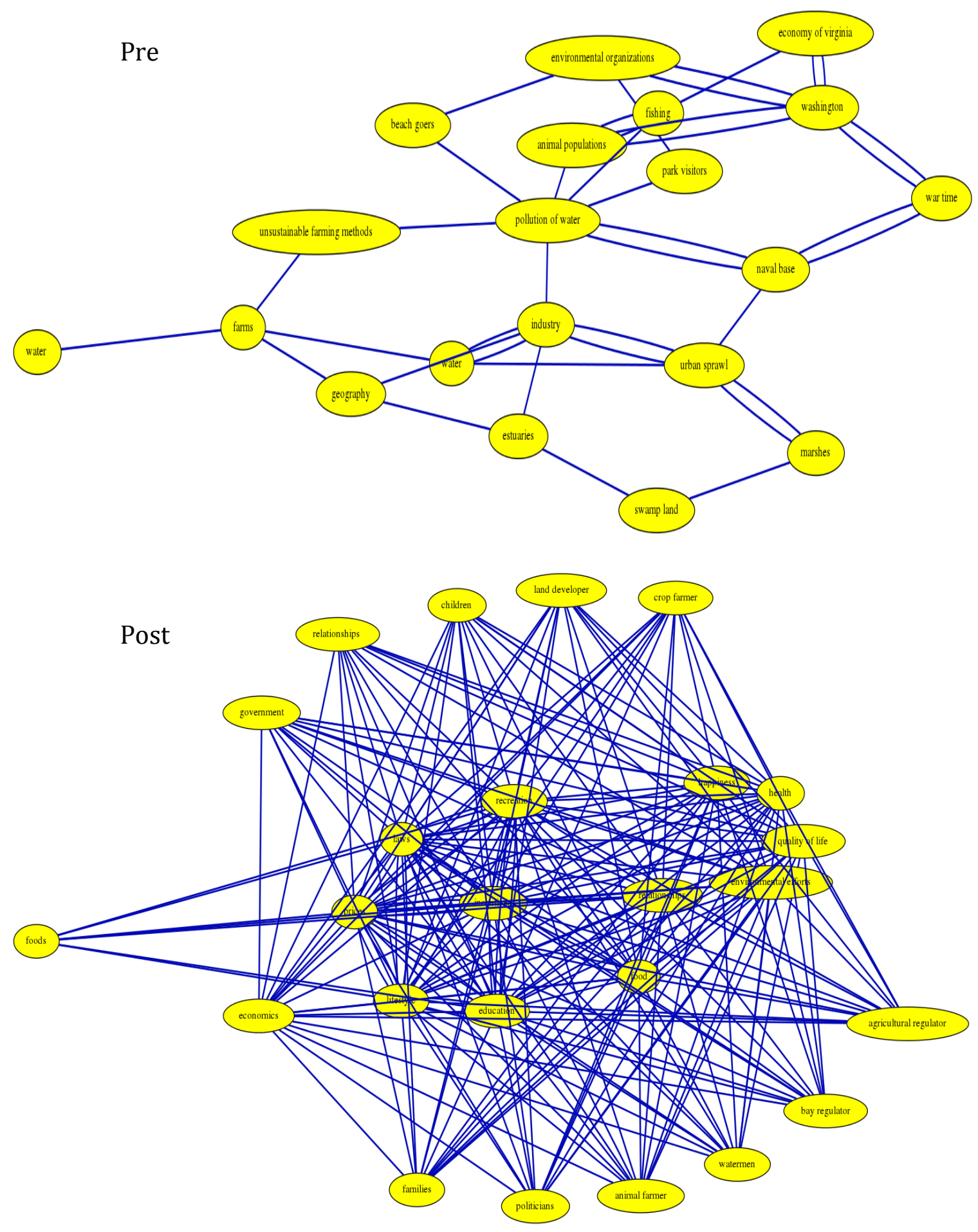

Figure 5. Example from the main data set of a concept map pair that graphically illustrates the structural differences from pre (top) to post (bottom) simulation. 
The results from the AKOVIA output indicate that changes between pre- and postconcept maps were present, but did not indicate the direction of change or level of statistical significance. In order to determine the magnitude of pre-post change, the individual descriptive data (i.e., number of concepts, diameter and number of vertices) were compared from pre to post to determine direction, significance, and magnitude of change.

Following a Shaprio-Wilk test that confirmed the assumption of normality, a paired ttest compared the structural differences between the mean pre- and post-simulation concept maps for individual participants across the sample. There was initially a positive, statistically significant difference in the scores for Number of Concepts $(\mathrm{t}=2.040, \mathrm{p}=.047$, Cohen's $d=$ $0.373)$ and Internal Vertices $(\mathrm{t}=2.027, \mathrm{p}=.048$, Cohen's $d=0.370)$, but not in Diameter of the maps $(\mathrm{t}=1.020, \mathrm{p}=.313$, Cohen's $d=0.173)$ (see Table 6). According to Cohen (1988), effect sizes of 0.3-0.4 are in the small to medium range. Across maps in this case, there were changes on two measures from pre to post indicated by the increase in the complexity of systems representations. However, the span or diameter of maps did not show significant change. Because the three tests were performed on the same data, a Bonferroni correction was applied, changing the critical value $(\mathrm{p}=.05 / 3=.016)$. While there were positive increases in differences in concept maps, these increases were nonsignificant using the Bonferroni-corrected critical value. 
Table 6

Paired T-test Results for Pre-simulation and Post-Simulation Concept Maps

\begin{tabular}{|c|c|c|c|c|c|}
\hline \multicolumn{6}{|l|}{ Measures } \\
\hline & $\begin{array}{r}\text { Paired } \\
\text { Differences } \\
\end{array}$ & $\mathrm{t}$ & $\mathrm{df}$ & $\begin{array}{l}\text { Sig. }(2- \\
\text { tailed })\end{array}$ & $\mathrm{d}$ \\
\hline & $95 \%$ & & & & \\
\hline & Confidence & & & & \\
\hline & Interval of the & & & & \\
\hline & Difference & & & & \\
\hline & Upper & & & & \\
\hline & Lower & & & & \\
\hline Number of Concepts-Post Number & 5.098 & 2.040 & 50 & .047 & .373 \\
\hline of Concepts-Pre & .040 & & & & \\
\hline Diameter-Post & 1.339 & 1.020 & 50 & .313 & .370 \\
\hline Diameter-Pre & -.437 & & & & \\
\hline Internal Vertices-Post & 5.074 & 2.027 & 50 & .048 & .173 \\
\hline Internal Vertices-Pre & .024 & & & & \\
\hline
\end{tabular}

\section{Expert Analysis}

Expert raters' comparisons of quality differences between pre- and post-simulation concept maps yielded 56 cases. Both raters agreed on 50 cases in the sample. Of the cases in which raters agreed, $43 \%$ were scored as improving from pre to post, 35\% were scored as declining from pre to post, and $21 \%$ were scored as quality not differing substantially between pre and post. These results indicate that in a majority of the cases, experts agreed that post simulation maps demonstrated an improvement in the complexity of the representation of watershed system.

\section{Quantitative Analysis: Case 2}

As in Case 1, differences between pre- and post-concept maps indicated change across all AKOVIA comparison measurements (Table 7). The SFM component demonstrated a change in the number of nodes $(\mathrm{M}=.616, \mathrm{SD}=.211)$. Further measures demonstrated change as indicated 
across outcomes for $\mathrm{GRM}(\mathrm{M}=.735, \mathrm{SD}=.163), \mathrm{CCM}(\mathrm{M}=.807, \mathrm{SD}=.143), \mathrm{GAM}(\mathrm{M}=.437$, $\mathrm{SD}=.174), \operatorname{STM}(\mathrm{M}=.163, \mathrm{SD}=.136)$, and $\operatorname{PPM}(\mathrm{M}=.320, \mathrm{SD}=.220)$.

Table 7

Outcome measure using similarity metric where $0=$ no likeness between maps and $1=i d e n t i c a l$ maps or no change for Supporting Quantitative Case.

\begin{tabular}{lccccc}
\hline Measure & N & Minimum Maximum & Mean & Std. Deviation \\
\hline Surface Matching (SFM) & 34 & .294 & 1.000 & .616 & .211 \\
Graphical Matching (GRM) & 34 & .375 & 1.000 & .735 & .163 \\
Concept Matching (CCM) & 34 & .388 & .996 & .807 & .143 \\
Gamma Matching (GAM) & 34 & .066 & .702 & .437 & .174 \\
Structural Matching (STM) & 34 & .000 & .444 & .163 & .136 \\
Propositional Matching (PPM) & 34 & .000 & .652 & .320 & .220 \\
\hline
\end{tabular}

As above, in order to determine the direction, significance and magnitude of changes in the preand post-concept maps, further analysis was required. The results of paired t-test (Table 8) are presented here, including effect sizes. 
Table 8

Quantitative Data Set Two Paired T-test Results for Pre-simulation and Post-Simulation Concept Maps

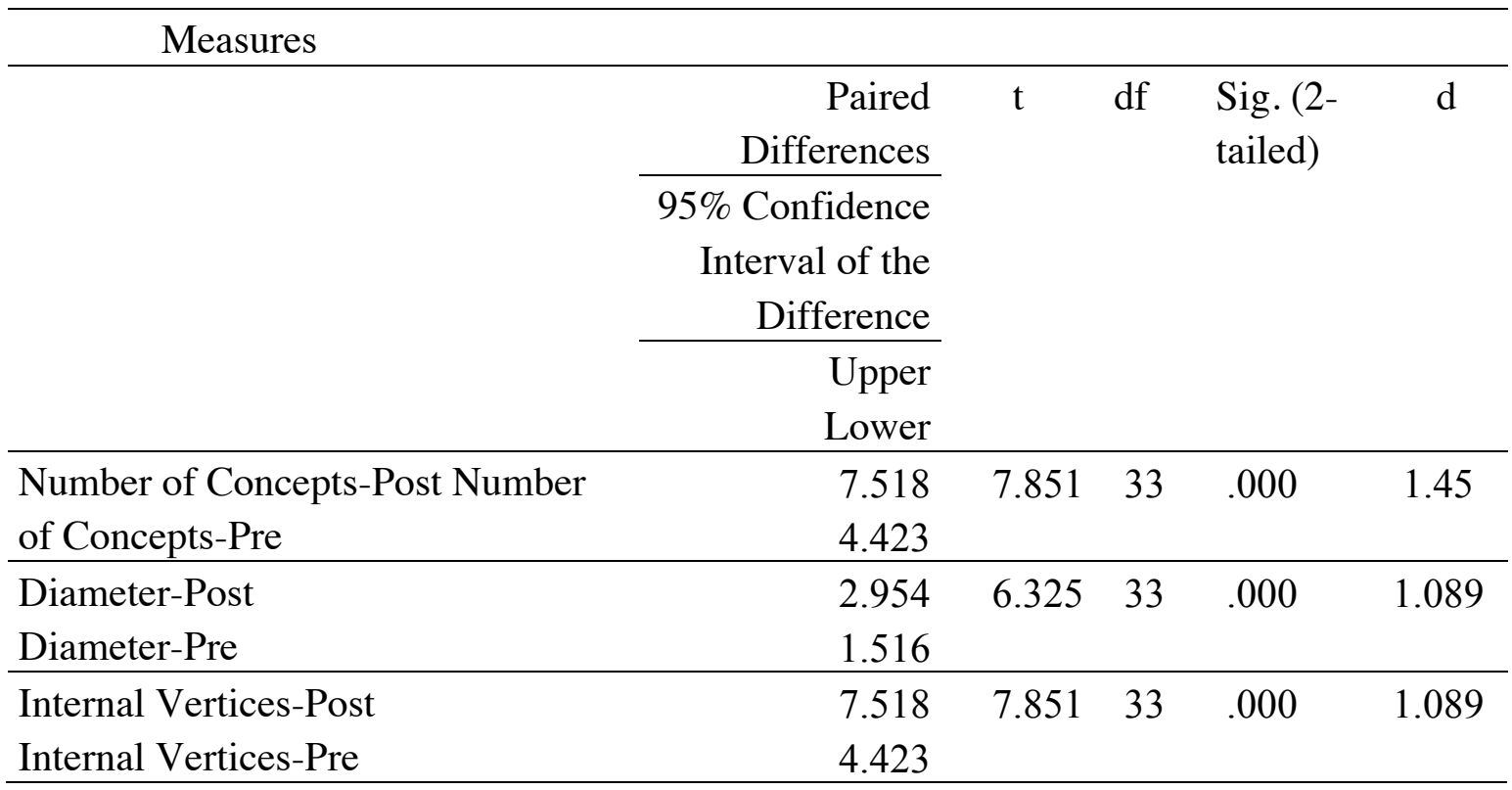

$N=34$

Unlike in Case 1 concept maps, all paired set comparisons yielded positive significant

differences from pre to post across the group, even when a Bonferroni correction was applied to the critical value $(p=.05 / 3=.016)$. All measures showed evidence of statistically significant change across individuals in the group. Differences across the group in Number of Concepts $(\mathrm{t}=$ $7.851, \mathrm{p}<.001)$, Internal Vertices $(\mathrm{t}=6.325, \mathrm{p}<.001)$, and Diameter of the maps $(\mathrm{t}=7.851, \mathrm{p}$ $<.001)$ indicated increased complexity from pre to post. Additionally, effect sizes of these measures were large (per Cohen, 1988) across Number of Concepts $(d=1.45)$, Internal Vertices $(d=1.089)$, and Diameter $(d=1.089)$.

\section{Qualitative Participant Reflections Data Analysis: Case 1}

Participants described the changes in their understanding of the watershed as a complex system and differences between pre- and post-simulation concept maps. Using an open coding scheme (Strauss and Corbin, 1988) based on the theoretical framework founded in complex 
systems understanding and situated cognition, the initial round of coding yielded 21 codes. In subsequent rounds of coding, themes that emerged from the data along with a priori themes that were established through the deductive coding process, progressed into more inferential codes and allowed the data to be examined for connections between participant descriptions of changes in their learning and complex systems understanding. In additional rounds of coding the researcher was able to broadly categorize the codes into complex systems understanding and situated cognition.

Table 9

Case 1 Qualitative Coding Scheme

\begin{tabular}{lll}
\hline a priori Codes & Inductive Codes & Larger Themes \\
\hline Accretion & Human Impact & Complex systems understanding \\
Adaptability & Macro to Micro & Learning Problems \\
Decentralized control & Oversimplification & Situated Cognition \\
Delay & Misconceptions & \\
Deterministic Centralized Mindset & & \\
Disjunctive effect & & \\
Emergence & & \\
Interconnectedness & \\
Linear Causation & \\
Micro to Macro & \\
Multilevel Understanding & \\
Multiple Causal Sources & \\
Pre Post Change & \\
Reductive Bias & \\
Re-organization & \\
Self-organization & \\
Tuning &
\end{tabular}

Evidence of changes in complex systems understanding emerged from the data, along with unexpected themes related to misconceptions, oversimplification and individualistic perspective. These emergent themes were categorized as they related to not only complex systems understanding, but also persistent learner difficulties identified in previous studies for 
example, the deterministic centralized mindset (Resnick, 1996) and reductive bias (Jonassen, 2006). Additionally, themes around the cognitive process of not only learning about complex systems, but also representing them with concept maps emerged as well. Although the researcher developed a priori codes related to the process of learning in complex domains like accretion, tuning, and re-organization, these data were not able to capture learning well at this larger grain size since the data did not provide specific enough information on the cognitive processes participants engaged in while developing concept maps. The descriptions of participants' changes in their concept maps from pre to post provided substantial evidence for increased understanding of complexity. However, participants also recognized the limitation of concept mapping as a means of "holding" their understanding due to the limited capacity of their working memory.

Participants also described moments of insight within the simulation where core principles were grasped. For some, these moments moved their thinking into a more in-depth understanding, while for others it moved their thinking toward misconceptions about the relationships between elements in the system as linear.

Complex systems understanding. Participant reflections in this data set demonstrated an overall increase in complex systems understanding as described from the participants' perspective. However, the nature of learning varied across participants. Nearly all participants described their experience as one that increased their understanding of complex system of the watershed. However, further analysis revealed that, although there were participants who described better understanding of the complexity, there was evidence in their reflections of a more constrained, linear perspective after playing the simulation. This next section will break down the reflection analysis results and themes that emerged across the data, including complex 
systems understanding, difficulties with complex systems understanding and cognitive and metacognitive concepts.

Interconnectedness. Participants most frequently reported in their reflections a deepened understanding of the number of elements in the system and their interconnections. These increases in understanding were described as the awareness stemming from game play of the increased number of elements in the system and their interconnections. One participant reported, "Everything was connected and reliant on each other." Another said of interconnectedness in the watershed system:

The main difference in my understanding has to do with not only the effect of environmental policy upon the health of the bay, but also the effect of local economic and development policy. While a normal regulation would just attempt to prevent the population from certain practices, the local development official had the power to influence subsidies, which would in turn affect the farming practices that each group chose. I suppose I was just amazed by how quickly and flexibly the behavior of the farmers could be changed due to the regulators decisions, and how quickly this could adversely affect the bay if the wrong choice was made.

Decentralized control, emergence, and adaptability. The category of

interconnectedness captured a large number of participant responses. It was then refined into the specific features of interconnectedness that were descriptive of the elements of complex systems understanding. Unique characteristics of complex systems, as described in the literature review include the elements of decentralized control, emergence, and adaptability. These concepts have been historically difficult for students to understand (Chi, 2000; Feltovich et al., 2001; Penner, 2000; Resnick, 1996). The concept of decentralized control was one that participants were able 
to articulate in their reflections of changes in their concept maps of the watershed. Evidence of understanding was described by participants as:

In contrast to my previous diagram set which generally organized the natural processes of the Chesapeake Bay into a somewhat linear cause and effect arrangement, whereas my later diagram takes on a more circular or web-like structure that begins to reveal the complex reality of the system. While there are still strong cause and effect relationships present, the phenomena are not biased to occur in one direction, taking into account the presence of feedback loops and reinforcing mechanisms that ultimately allow for the system to take on its essential, self-regulating nature. Through the existence of these multiple connections backwards and forwards throughout the system, inter system communication is highly improved, strengthening resiliency and vitality over time. Another participant observed: In my first diagram I went through the basic elements of farming, fishing, economic factors, etc.; but in my second diagram I got more specific using the bay game roles to provide more detailed information that furthered the relationships between my initial elements. I realized that that the players in the system not only had more complex relationships with the overall health and functions of the Chesapeake but they also have incredibly complex relationships with one another. The hierarchy and interconnections that can be illustrated are almost never-ending depending on how closely you look at the roles and actions of each player and element.

Emergence as a concept was most effectively captured by participants' conceptualizations that described the multiple levels of interactions and causes among the concepts of adaptability (resilience) and self-organization. These more refined categories 
developed from the first much broader categories of interconnectedness and emergence. Some participant responses that were coded as multi-level understanding or micro/macro view understanding included statements like:

The main reason that my diagram has changed is that I now have a better understanding of who is involved in the system. I considered how regulations, laws, and incentives play a part in the system which is something that I previously had not thought about. I also included how personal gain plays a part in the system as people are trying to make money off the bay which may not always lead to actions that are beneficial to the health of the bay.

Additional evidence of emergence was described by another participant as:

The key changes to my diagram and understanding of the Bay have to do with the amount of elements that can directly affect the Bay's Health or the way we interact with it. I had previously assumed the majority of the Bay's Health issues came from small disruptions, such as human development, to the natural system that had grown to destabilize it. What I have learned is that, while this is true, I failed to think of other elements, which have a direct effect either on the bay's health or which have a direct effect on factors that govern the bay's health, such as economics and feedback loops such as fishing and the wildlife stocks. Having noticed these new elements I have also noticed that there are many more relationships between all these elements than I had previously thought, complicating the system by far more than I had imagined.

Further participant evidence of emergence was described as:

I see the bay as a much more complex system of natural systems as well as economically driven, human oriented, un-natural systems. The diagram for question one is much more 
"wordy" because after the game I see a majority of the health of the bay as decisions between being sustainable and being economically productive. I think it is hard to diagram a balanced model of the bay because we haven't found a way to even come close to a balance. I also see the main source of pollution not as just the byproducts of human life and waste but as byproducts that stem from economically driven decisions.

Delay. Participants also captured the concept of delay in their responses, which could also be a demonstration of increased understanding in the complexity of the system and its interconnections. For example, one participant wrote, "By directly participating in the Bay Game, I was able to more directly see the long-term consequences that my actions had on the economic and environmental health of the larger system around me over time." This participant describes delay and the advantage that the simulation has in helping him see changes on multiple levels over time.

Difficulties in understanding complex system concepts. While nearly all participants reported an increase in their understanding of the complexity of the watershed system, further analysis revealed that some still maintained (or developed) a linear understanding of those connections, others had developed misconceptions (usually around direct causal inferences), while others held onto the deterministic centralized mindset (mostly centered on human impact) (Resnick, 1996). Further, some participants who experienced the simulation and tried to make sense of the complex system, also experienced oversimplification in their thinking and cognitive phenomena like reductive bias (Jonassen, 2006). Additionally, some participants, as the result of taking on a role in the simulation, had difficulty mentally stepping back to describe their role as a part of the system. These responses were categorized as individualistic perspectives that 
demonstrated the inability for a participant to fully understand or describe a multi-level perspective.

Human Impact. The data revealed that many participants understood from the playing the UVA Bay Game that human impact was a major causal factor in the decline of the health of the bay. This theme was evident across reflections in both participants who had a welldeveloped understanding of the watershed as a complex system and those who had developed misconceptions. However, for those who developed misconceptions or an oversimplified perspective, human impact was considered a more linear causal explanation that was described without consideration for the complexity of interactions between natural systems and functions and human systems. One participant reported, "I assumed that these changes were due to the natural evolution of the earth's geography over time, when in reality, these changes are often the direct consequences of land and technology use by humans." Another stated:

At first, I did not consider the individual people to be elements in the system, but rather I modeled the consequences of these individual occupations, such as pollution, erosion, over-fishing, etc. and their affect on the bay. The Bay Game crystallized the real causes of these and pared them down to their human agents. My new diagram is much more linear and focused on the root of the Bay's problems, humans.

Further evidence of oversimplified human impact was described, "Only [k]now, with human activity on such a large scale has the balance of the system come under threat. Thus, we should focus majority of our attention upon dealing with our "unnatural" interventions into these systems."

Another participant moved between either/or causal reasoning by stating: "My understanding of the bay has changed from one that focused mostly on the environmental 
aspects to one that focuses more on the role of human interference, specifically in the forms of regulation and legislation."

Oversimplification/reductive bias. As reported in previous studies (e.g. Spiro, et al., 1992, Jonassen, 2006), when participants pare down their understanding to a level that does not encompass the multiple elements, levels of interactions, and interconnections within a system, this is known as reductive bias or oversimplification. This difficulty was evidenced in participant reflections as well:

As I said, I initially visualized the Chesapeake Bay watershed system as a web of elements and interconnections. I now understand this chain of actions and consequences to be much more direct.

Another participant presented simplification of the system by stating, "Instead of looking at the secondary \& tertiary problems, this diagram shows more a focus on the primary system. E.g. the crop farmer $\rightarrow$ crop yield + nitrogen/phosphorus run-off $\rightarrow>$ bay." Similarly, another participant described:

This can be seen as a one way relationship, the bay is used by man for harvesting food, dumping chemicals, and transportation. What I began to see though is that the bay is really a recycling system. What man takes in and out of the bay is just reinserted into the system at another point in the future. When the bay is mistreated, this recycling becomes harmful and expediates the process of decay. What the bay is used for becomes less successful. There is a disconnect from the idea of using the bay to harvest and using the bay to dispose, this is where man begins to recycle harm upon itself. 
This last reflection demonstrates reductive bias much like that discussed earlier when describing the water cycle as a set of discrete steps that does not account for the adaptability or emergent properties of the complex system.

Summary. The qualitative analysis of the participant reflections on their own understanding of the changes between their pre- and post-maps were generally demonstrative of an increase in their understanding of the watershed as complex system. Participants were able to reflect on a deepened understanding of the number of elements, the number of interconnections and multi-level causation. Participants described difficult complex systems phenomena like emergence and decentralized control. However, noted in some participant reflections, were misconceptions about complex systems, like the oversimplification of levels, causal influences, or outcomes. Further, some participants actually moved to a more linear understanding after engaging with the simulation as opposed to more complex one.

\section{Qualitative Participant Reflections Data Analysis: Case 3}

These data were analyzed to evaluate the convergence between Case 3 and the participant reflection evidence from the Case 1. As described in Chapter 3, Case 3 data were collected from a subsequent section of the architectural systems course used in Case 1 analysis. However, the participants in this data set were given slightly different directions for their reflections: "In a short paragraph, describe an experience that you had during the game play that led to a new insight about the system or a deeper understanding of the processes at work." Participant reflections in this supporting case were analyzed using the same process as described for the qualitative analysis of the participant reflections in Case 1.

Initial rounds of coding this data set yielded 21 codes. Additional codes in this data set yielded several representations of concepts not evidenced in Case 1 that centered around 
participant learning, teaching, and interactions with classmates and the simulation. The next section will describe the findings from this supporting case and the additional emergent themes.

Table 10

Case 2 Qualitative Coding Scheme

\begin{tabular}{lll}
\hline a priori Codes & Inductive Codes & Larger Themes \\
\hline Accretion & Human Impact & Complex systems understanding \\
Adaptability & Macro to Micro & Learning Problems \\
Decentralized control & Oversimplification & Situated Cognition \\
Delay & Misconceptions & \\
Deterministic Centralized Mindset & Classroom Instruction & \\
Disjunctive effect & Teaching & \\
Emergence & Collaborative environment & \\
Interconnectedness & & \\
Linear Causation & & \\
Micro to Macro & & \\
Multilevel Understanding & & \\
Multiple Causal Sources & & \\
Pre Post Change & & \\
Reductive Bias & & \\
Re-organization & & \\
Self-organization & & \\
Tuning &
\end{tabular}

Explicit connections in complex systems understanding were clear from this data set.

The responses to the prompt were in-depth analyses of the participants' understanding of their changes in understanding the watershed as a complex system. Participants clearly articulated the elements, connections and interconnections within the system. All participants in this case described their learning in terms of increased understanding of the complexity of the watershed. Further, participants demonstrated a clear understanding complex systems principles like emergence and adaptability through the use of feedback loops in their diagrams, which allowed them to expand their concept maps and incorporate larger representations. 
Complex systems understanding. From the perspective of all of the participants in this data set the gains in their learning from pre to post simulation were evident. The participants described an increase in their understanding of the complexity of the watershed system through rich descriptions of the systems that included concepts of interconnectedness, emergence, micro to multi-level understanding, decentralized control and adaptability.

Interconnectedness. Participants described the watershed as an interconnection of elements on multiple levels, like one participant who wrote, "Some may take the form of reinforcing feedback loops that stabilize the relationship between the players and the watershed, but in the end every decision affects the system as a whole and the relationships between the elements." Another wrote:

It allowed me to understand in a much clearer way the way a system works and how it is broken down to different elements that are all connected and affect each other even if they seem as if they do not. It was very interesting to use a real example, which helped me grasp it better. It also made me realize how much actually goes into a system and how important every role actually is, as I did not really think there were that many factors that all affected the health of the bay together. In addition to that, the game showed us that every decision you make, thinking it is a good one, might negatively affect someone else playing another role.

Decentralized control, emergence, and adaptability. Decentralized control, the idea that there is not a single entity controlling a system, was evidenced through participant responses like:

Decisions such as implementing pest management to discourage the use of pesticides, monitoring systems to report on environmental damage and subsequent fees, taxes, and 
bonds in order to lessen the discrepancy between public costs and private benefits of environmental decisions will all act as balancing or reinforcing feedback loops for the system as a whole and will therefore benefit both financial gain and bay health. Incentives, punishments, and constraints - whether implemented as social rules or physical laws or policies - hold a lot of power over the decision-making process and therefore the processes of the system as a whole.

Decentralized control was a concept that participants were able to really capture more clearly in their reflective responses in comparison with concept maps. Another participant stated:

During the simulation, I realized that each section can post some effects on the system, but the overall result is not easily influenced by one factor. For example, after the first round, bay health decreased noticeably. As a land developer, I bought more sustainable Greenfield in order to increase the health level. However, this action has minor effect on the whole system and the nitrogen and phosphate level is still not decreased after the next round. A reasonable explanation for this would be the effects brought by increasing Greenfield are neutralized by other actions in the opposite direction.

From responses like these participants described the understanding that, despite there control over particular elements in the simulation of this complex system, elements were interconnected and that power to make changes directly in the system was difficult since no one entity was in control. Further, the concept of emergence, order arising from seeming chaos or randomness, was described by the participants, as well. One participant reported:

By buying sustainable infill and greenfield however, land developers not only raise its value on the market (since its steady supply is relatively low), but also help to change the way people view sustainable practices. If others involved in the market begin to the 
see the demand for sustainable development increase, behavior will change as more investment into that kind of practice is made. Through the bay game, I learned individual choices matter just as much as those on a large scale.

One very clear statement of understanding emergence was described succinctly as, “...small shift in one thing can produce big changes in everything." Or, as another stated:

Each piece information needed to be carefully thought out and planned, and even the smallest gameplay element had major impacts for the game. The intricacies of the Bay Game start to show how complex real life systems are, and the importance of the smallest decision.

Additionally, adaptation or adaptability was a phenomenon the participants described with surprise, for example, when they would make a change in their decisions to affect a certain outcome, only to find the outcome persist or even increase because of other factors influencing the system.

Difficulties in understanding complex systems concepts. In this data set, participants exhibited some misconceptions in their understanding, as well, although with fewer instances, relative to the first data set. Additionally, a small number of participants in this group also experienced, reductive bias or an oversimplification of the workings of the system in their descriptions. As evidenced in this participant's response, "Looking at this graph, I can say that my income is somewhat directly proportional to bay health. As my income increased, bay health increased and as my income decreased, bay health decreased." In this and the following responses, it is evident that the participants have a simplistic understanding of the causes (and therefore, solutions) to the decline of bay health. 
The Regulators are able to enforce policy in order to protect certain aspects of the Bay's health and wellness. Though there are a vast amount of policies that could be enforced in order to better the Bay, take for example the enforcement of immediate jail time for pollution in Chesapeake waters. This would vastly change the dynamics of the Bay's livelihood.

As another participant offered, "The thought behind the [above] ideas is that instead of using tax payers money to give incentives, you highlight those who are causing the most pollution and tax them higher."

Lastly, some participants in this set experienced the concept individualistic perspective, which means they described the system from the perspective of their role, but did not articulate multiple levels of causation. For example:

I realized that it is a crop farmer's own motivations that affect his decisions. I had been more focused on making a profit rather that improving the health of the bay, which is why I switched back to conventional farming after trying organic. I guess I figured I could get rich while everyone else focused on increasing the health of the bay. I figured that the runoff that my farming produced would have a very minimal affect on the overall health of the bay. If I had been more focused on improving the health of the bay, then I probably would have continued farming organically; especially because the incentives were still high so my difference in profit would not be too far off from the profit earned from farming conventionally. The positive effect on bay health would have be worth farming organically to me.

Summary. The participant reflections in Case 3 described positive outcomes in their changes in understanding between pre- and post-simulation concept maps. These participants 
reported largely a complete understanding of the process, interactions, and elements at work in the watershed system. Further, participants were able to describe the changes in their understanding with specific complex systems terminology that demonstrated a clear understanding of reinforcing feedback loops, emergence and adaptability. Although the responses generally demonstrated an increased understanding of the complexity of the watershed system, there was still some evidence of misconceptions-mostly in the form of oversimplification. 


\section{CHAPTER FIVE}

\section{DISCUSSION}

This chapter presents an overall discussion of the findings across all data analyzed in this study and cross case analysis. The first section will discuss the results and implications and the following section will discuss limitations and avenues for future research.

\section{Purpose of Study}

In light of the call from the science community to fulfill the need for a better understanding of complex systems (American Association for the Advancement of Science Project 2061, 2009), the need for innovative approaches to teaching complex systems understanding, the conflicting research on the effectiveness of simulations for learning, and the lack of understanding regarding optimal simulation use during instruction, this study set out to examine a particular complex systems simulation and explore how it might be helpful in the teaching of complex systems and how participants experienced learning with the simulation. In order to gain insight on learning in this environment the following questions were used to guide the study:

1. Is the use of an agent-based, participatory simulation of a watershed system associated with an increase in undergraduates' understanding of system complexity?

2. How do participants describe their changing understanding of the system associated with simulation use? 


\section{Summary of Findings}

Overall changes in participant-developed concept maps of the watershed system yielded positive results in terms of demonstrating evidence of quantitatively distinguished differences from pre to post simulation. Pre- to post-concept map changes showed positive but statistically nonsignificant differences across both the physical and semantic structure, demonstrating an overall increase in complexity of the participants' knowledge of the factors relevant to the Chesapeake Bay as a coupled human and natural system. The addition of the expert analyses of concept maps strengthened the Case 1 quantitative results. Positive results were evidenced by the expert analyses of the map quality, which indicated that more of the participants' postsimulation concept maps demonstrated improved understanding from the pre-simulation concept maps. Findings from Case 2 also yielded positive trends, but did so at a statistically significant level with large effect sizes.

Further, supporting evidence was provided by the in-depth analysis of participants' reflections on their learning. Case 3 analysis of participant reflections on learning converged well with the qualitative findings in Case 1. In addition to positive changes in understanding of complex systems, other important outcomes were identified that included the reinforcement or development of misconceptions, the sustained issue of oversimplification or reductive bias, and the constrained representation dilemma, which will be discussed more extensively below.

\section{Cross-Case Analysis}

Case 1 examined 51 participants across three separate analyses to determine if participants experienced an increased understanding of the complexity of the Chesapeake Bay watershed system with the use of a simulation and how participants described changes in their understanding between pre- and post-simulation concept maps. Case 2 examined data from 31 
participants in an effort to replicate the quantitative findings from Case 1. Case three examined data from 51 participants for the purpose of detecting convergence with the qualitative data captured in participant reflections in Case 1 (Table 11).

Table 11

Evidence Across Cases in Support of Findings

\begin{tabular}{|c|c|c|}
\hline Case 1 & Case 2 & Case 3 \\
\hline $\begin{array}{c}\text { Positive but insignificant } \\
\text { changes in complex systems } \\
\text { understanding quantitative } \\
\text { measures }\end{array}$ & $\begin{array}{c}\text { Positive and significant } \\
\text { changes in learning outcomes } \\
\text { with quantitative measures } \\
\text { (replication) }\end{array}$ & \\
\hline $\begin{array}{c}\text { Positive evidence of change } \\
\text { in 43\% of expert ratings }\end{array}$ & & $\begin{array}{c}\text { Narrative reflections yield } \\
\text { positive evidence of }\end{array}$ \\
\hline $\begin{array}{c}\text { Narrative reflections yield } \\
\text { positive evidence of } \\
\text { increased understanding of } \\
\text { complex systems, with some } \\
\text { evidence of misconceptions }\end{array}$ & & $\begin{array}{c}\text { complex systems } \\
\text { (replication) }\end{array}$ \\
\hline
\end{tabular}

The quantitative concept map data from Case 1 indicates positive evidence of changes in complex systems understanding that was supported with both structural and semantic increases in the complexity of participant concept maps on all measures except one. Although, those results were not significant, they did yield modest positive effect sizes. Case 2 provided more robust positive findings by yielding significant increases in understandings of complex systems with large effect sizes after the Bonferroni correction was applied. The differences in these two cases may be due to the variability in the data from Case 1. Because there were reasonable effect sizes in Case 1, this indicates that there could have been a power problem and that a 
larger sample size could have made a difference, despite this variability. Additionally, this variance may have been due to factors outside of the researchers control like how the participants were making sense of the game or how they were instructed on concept map development or a lack of constraints (e.g. vocabulary lists) in Case 1.

The participants' own words describing the changes in their understanding triangulated the quantitative and qualitative concept map data from Case 1. Participants reflected on their understanding and reported an increase in the complexity of the watershed systems they had mapped after the simulation, describing understanding of difficult complex systems concepts, like emergence, decentralized control, and self-organization. Participants in both Case 1 and Case 3 described the changes in their concept maps as increased understanding of complexity. The second set of participant reflections demonstrated an in-depth understanding of the watershed as a complex system. These descriptions were more detailed that those from the Case 1 and these differences will be discussed later in this chapter.

Using the convergence of these participant reflection data, the evidence indicates that participants did experience a change in their understanding of the Chesapeake Bay watershed system as a complex system, and that their changes were demonstrated as increases in complexity understanding. Participants articulated the changes in their concept maps between pre- and post-simulation as increased understanding of complexity, as well. Although almost all participants reported increased understanding of the complexity of the watershed system, a few who reported an increased understanding of complex systems in both cases, actually described an oversimplification or misconceptions about the system. The scope of this study did not allow the researcher to determine if the misconceptions were pre-existing and the simulation 
reinforced them, or if the simulation actually led the participant to interpret the system as more linear.

Understanding complex systems is a historically difficult topic of study for students. Further, capturing understanding of complex issues can be difficult as well. The data indicate that participants experienced increased understanding of the watershed system with the use of the UVA Bay Game. However, these results are exploratory and meant to describe the changes and participant perspective on those changes for this particular study. The next section will detail the interpretation of these findings and implications for future research.

\section{Interpretation}

\section{Nature of Learning With the UVA Bay Game}

Results in this study yielded multiple possible reasons and mechanisms for improved learning about complex systems with the UVA Bay Game. Rooted in the theoretical framework of mental models and situated cognition, the UVA Bay Game demonstrated instructional design qualities that could potentially be connected to complex systems understanding. Positive pedagogical approaches embedded in the simulation, along with experiential learning opportunities and collaborative problem solving were also factors that may have contributed the learning outcomes described. Additionally, the unique affordances of the simulation environment to which increased complex systems understanding may be attributed are discussed. In addition to the elements that may have been positively important in the nature of learning about complex systems with the UVA Bay Game, there were also issues of misconceptions that need to be considered in the interpretation. 
The UVA Bay Game simulation. Participants engaged with the UVA Bay Game in the context of their regular classroom activities experienced a positive change in their understanding of the Chesapeake Bay watershed as a complex system. Multiple factors may contribute to this increase in understanding that can be attributed to the unique affordances provided by the design and use of the UVA Bay Game for learning. Unique affordances of simulations in the research on complex systems understanding have been demonstrated as the ability to help participants learn by taking on roles, analyzing data, making decisions and refining decisions based on feedback (Seel et al., 2009).

The UVA Bay game provides the context for learners to engage as actual stakeholders in the watershed giving them a unique perspective that they may not be able to experience in real life. Participants, as stakeholders in the UVA Bay Game, have the advantage of experiencing situations and outcomes in a short period of time that, in reality, would take many years to play out. This move through time allows participants to engage with inductive sense-making as they experience the emergence of patterns over time, or the effects of delay on the complex system (Blumschein et al., 2009). As described by the participants, these attributes of simulations may have been instrumental in learning outcomes. One participant reflection described delay as: Another problem that I noticed was the delay in results. This is also related to the problem of selfish actions, in that people don't realize the consequences of their decisions until years later, when the bay health suddenly deteriorates. The immediate benefit of the profit prevents people from considering the future problem of the bay's health, lower crab population, and less profit that can be made.

Pedagogical elements in the simulation. One potential reason for the increased complex systems understanding may be due to the underlying design of the UVA Bay Game, 
which capitalizes on situated cognition to help participants develop mental models of the system (Jonassen et al, 2005). As described by Johnson-Laird and colleagues (1998), participants engaged in the UVA Bay Game are able to develop mental models, draw conclusions about actions to be taken, and test the validity of their assumptions through execution of their decisions. The ability to manipulate situations and then interpret the outcomes of those decisions as well as think through potential consequences are fundamental in the development of learning with mental models (Jonassen, 2006). The UVA Bay Game employs collaborative problem solving (Johnson \& Johnson, 2009), time for reflection, the ability to observe and make iterative changes, all of which have been demonstrated as effective pedagogical approaches to complex systems learning (Jacobson \& Wilensky, 2009)

Misconceptions. Limitations to human cognitive capacity can lead to misconceptions about the processes of the system when learners are unable to juggle multiple models and learners reduce the system to the extent that its complexity is oversimplified. Participants who developed mental models of the Chesapeake Bay watershed system described this phenomenon in their experiences stating:

Looking at this graph, I can say that my income is somewhat directly proportional to bay health. As my income increased, bay health increased and as my income decreased, bay health decreased. From this graph, I can see that I play a big role in maintaining the Chesapeake Bay health.

It is evident in this participant's description of the system that they have developed (or confirmed through game play) the misconception that there are linear causal relationships that contribute to bay health. Another participant reflected: 
The thought behind the above ideas is that instead of using tax-payers money to give incentives, you highlight those who are causing the most pollution and tax them higher. This encourages people who produce high pollution levels to cut that level and also it won't penalize those who are already straining to live a low pollution lifestyle. This participant describes an oversimplified solution to improving the bay's health by not recognizing the relative interconnectedness among stakeholders and the fact that not one group can be directly responsible for quantifiable negative effects on the system. This participant fails to see the relative connections between the stakeholders and the non-linear, non-direct relationship of the actions of the stakeholders on the health of the bay and the economy. Oversimplifications and direct, linear-causal thinking were the only evidence of descriptions of misconceptions in participant reflections. Determining the root of those misconceptions and making adjustments either through teaching, changes to the simulation, or both, are important design considerations to be gleaned from this research.

Past research (e.g. Sengupta \& Wilensky, 2009) indicates that misconceptions like reductive bias, deterministic centralized mindset and linear-causal thinking are difficult to overcome. Because there was not enough evidence collected in this study to determine the origin of these misconceptions, it is hard to determine what, if any, role the UVA Bay Game had in reinforcing or developing them. Although the origin and nature of the misconceptions was beyond the scope of this study, these are important considerations for subsequent design that need to be addresses in future research.

\section{Limitations and Delimitations}

The goal of this study was to examine the potential affordances of the use of a particular agent-based simulation as a learning tool for increased understanding of complex systems in 
three courses. Further, this research seeks to provide a framework to help identify in future studies the particular characteristics of the UVA Bay Game that may contribute to increased understanding of complex systems in an effort to enhance and maximize the pedagogical uses of this simulation for learning. Understanding if and how this particular simulation aids in complex systems understanding will further refine the design of the simulation and curricular materials that will accompany it.

The representativeness of this sample is limited by the fact that participants were enrolled in two particular majors (architecture and environmental science) at a highly-ranked university in the Southeastern United States. Additionally, participants in this study were situated within specific courses, with Cases $1 \& 3$ being different offerings of the same course. An additional limitation of this study is the nested nature of the courses in which participants were enrolled. Further, the readings, and contextually based learning experiences that would be part of these courses cannot be accounted for in the data collected in this study and it is beyond the scope of this research to address the extent to which these contextual factors may have impacted participant learning outcomes. Examining the differences in the significance of the Case 1 and Case 2 data, it is plausible that perhaps a larger sample size would have yielded significant results and there was a power problem, especially as indicated by the moderate effect sizes. Although the results from this study will not be inherently generalizable beyond the participating sample, they will be able to serve as an exploratory foundation for further research by highlighting an approach to participatory simulations that could contribute to the development of complex systems understanding.

An additional potential limitation in this research could be due to the quality of the concept maps collected during this study. Participant concept maps were developed by hand, as 
opposed to with the use of computerized mapping software, without the use of standardized terminology, which made the comparison of concept maps difficult. Standardization could have constrained content in the maps in such a way that there may have been a more precise or a more fine-tuned capture of the differences between and across individuals and groups. However, there is a delicate balance between providing constraints in order to create measureable concept maps and restricting the participants' representation of their own knowledge.

Without the explicit knowledge of the classroom environment and content being taught in the weeks leading up to and during this experience, we are restricted in our understanding of the role and specific contributions the teacher and pedagogy contribute to these results. Examining these key factors is an essential goal for future research.

Lastly, the focus of this study was understanding of the complexity of the watershed system with the use of the participatory agent-based simulation. Because of the design of this study and the nature of data collected, limitations in the ability to tease out key features in the simulation, teaching environment and supporting materials that contributed to learning in this context prevent us from making assertions about specific elements in the design of any of these factors that, explicitly or implicitly, contributed to learning outcomes.

\section{Implications and Future Research}

This exploratory research examining complex systems learning and agent-based participatory simulations is an introductory analysis for future studies that should focus on refining what elements and constructs of simulations and the teaching environment with simulations can best contribute to complex systems understanding and how to best utilize simulations in the classroom. This could be accomplished through a more controlled research 
design including the use of a control group, comparing a traditional, lecture-based, classroom with features of effective pedagogy like collaborative problem-solving and opportunities for discussion, with a classroom where the UVA Bay Game is the treatment. Holding all other features constant, to the extent possible in a classroom (not discounting the inevitable variance between classrooms), one may be able to isolate differences in the two environments and, more specifically, make connections between the simulation and learning.

\section{Future Use of Concept Mapping}

After completing the expert analysis of the hand drawn concept maps, experts reported that there were some pre- and post-simulation maps that could not be determined to be "better" or "same" due to the fact that they were so different from one another. Future research can strengthen findings through a more standardized concept map protocol for participants and explicit concept mapping instruction. With more standardization and a word bank, experts may be able to make clearer distinctions in the quality between maps using the standardized output from AKOVIA.

There is a delicate balance between providing constraints in order to create measureable concept maps and restricting the learners' representation of their own knowledge. This tension was reported by some participants in their reflections. Participants recognized their inability to accurately capture their understanding of the system in a concept map as a result of them "being too big." Some participants began their reflections with a disclaimer that acknowledged their maps were unable to fully capture the extent to which they understood the complexity of the watershed and the caveat that they were representing only a portion of how they saw the watershed system. One participant reported: 
There are so many factors that contribute to the health of the Bay. A lot of these factors are almost impossible to get a firm grasp on. I believe my first diagram achieved a general understanding of the problems the Bay is experiencing, but didn't quite get at the more specific sources of these problems. After re-diagramming, I realized that my first iteration only addressed the interconnection aspect of the Bay, with only slight credence to the different elements. Now I have a better understanding of the Bay's elements, interconnections and functions, which for a complex system of relationships at various scales.

These articulations were able to shed more light on the measured differences between maps alone and gave insight into more detail of the participants' knowledge about complex systems. Where it may have appeared a participant's post-simulation map was less complex after game play, their reflections were able to capture in words a more in-depth understanding, as well as difficulties the participant may have encountered trying to reduce the complexity of the system into a concept map like the participant referenced above. Future research should maintain multiple data sources in order to provide a complete understanding of the participants' knowledge and growth.

As noted in the reflection findings, there was some evidence of misconceptions that emerged from the data, in the form of oversimplification and direct causal relationship descriptions. What was not clear in these data was whether or not the oversimplification of the system was due to reductive bias, the concept of reducing a mental model because of limited cognitive capacity. Further, it was not clear whether or not the misconceptions were pre-existing or whether the misconceptions resulted from interaction with the agent-based simulation. While the source of misconceptions and oversimplification was not clear, it was evident that data from 
Case 3 reflections contained almost no misconceptions from oversimplification. This difference between Case 1 and Case 3 could be due to differences in the teaching that occurred between these two cases. For example, the reflections in Case 3 were much more detailed in terms of the participants' use and description of causal and feedback loops and the evidence of multi-level understanding and emergence. While this study did not capture the pedagogical component, it seems plausible that there was perhaps more teaching in complex systems in general in Case 3 as compared to Case 1 from the participant reflection results. What future research should examine is whether the differences in teaching may center on concept mapping and causal loop diagrams, or explicitly on complex systems. Future studies should additionally consider the pedagogical piece more explicitly in order to better understand the combination of teaching and simulation engagement in complex systems learning. By providing clear instruction on the design of concept maps and the providing a word bank, future studies should provide enough constraints so that measures can capture a more fine-tuned representation of student understanding. Explicit teaching of the kinds of connections and interconnection of concepts would be helpful in providing a richer representation of student understanding. Further, capturing the context of the classroom using techniques like graphing or networking analysis and discourse analysis could shed light on the role that the context plays in learning with the simulation, as well.

Because this research was intended to begin a body of evidence from which we could build to help understand how a particular simulation might be used to increase complex systems understanding, it helps define future research and refine the design and kinds of questions that should be answered next. From the evidence gathered, it does appear that, in combination with 
explicit concept mapping and complex systems instruction, the affordances of the simulation may be helpful in developing complex systems understanding.

Participants in this study experienced an increase in complex systems understanding as evidenced through concept maps and participant reflections on their learning. Future studies should include measures of the participants experience with collaborative problem solving, mental model creation, and other specific affordances that have been attributed to agent-based simulations in the literature. Additionally, future studies should include a pre-simulation and follow-up interview with participants that might more accurately capture the pre-existence of misconceptions. This could help us understand whether or not misconceptions are developed through engagement with the simulation or whether participants perhaps experience a confirmation of the pre-existing misconceptions like those of the deterministic centralized mindset.

Lastly, it would be beneficial in future research to determine if the affordances that participants experience in this context are unique to the use of the agent-based simulation, or if they are perhaps the result of other underlying pedagogical and cognitive or contextual experiences at work. With the use of a quasi-experimental design, future studies examining the use of the agent based simulation against another classroom instruction technique might be useful in identifying constructs that maximize the learning benefits in this environment. Additionally, understanding exactly what the components are that contribute to positive learning outcomes, can be helpful in the design and future iterations of simulations that are built for complex systems understanding.

Knowledge gleaned from this research has lead to an explicit path for future work on the UVA Bay Game. As we move forward with this research, questions about how complex 
systems understanding with a simulation can be deepened. This will contribute to a body of work that can ultimately be more generalizable for understanding the role of specific design features of simulations, the classroom context and other teaching materials, and the interactions between students, and how those elements factor into complex systems learning. 


\section{References}

American Association for the Advancement of Science. (2009). Benchmarks for Science Literacy. Project 2061. New York.

Assaraf, O. B. Z., \& Orion, N. (2005). Development of system thinking skills in the context of earth system education. Journal of Research in Science Teaching, 42, $518-560$

Augustine, N. R. (2005). Rising above the gathering storm: Energizing and employing America for a brighter economic future. Washington, DC: National Academy of Science, National Academy of Engineering, Institute of Medicine, National Academy Press.

Bankes, S. C. (2002). Agent-based modeling: A revolution? Proceedings of the National Academy of Sciences, 99 , 7199-7200.

Blikstein, P., \& Wilensky, U. (2005). Less is more: Agent-based simulation as a powerful learning tool in materials science. IV International Joint Conference on Autonomous Agents and Multiagent Systems (AAMAS 2005), Utrecht, Holland.

Blumschein, P., Hung, W., Jonassen, D., \& Strobel, J. (Eds.). (2009). Model-based approaches to learning. The Netherlands: Sense Publishers.

Bonabeau, E. (2002). Agent-based modeling: Methods and techniques for simulating human systems. Proceedings of the National Academy of Sciences of the United States of America, 99, 7280.

Bronfenbrenner, U., \& Evans, G. W. (2000). Developmental science in the 21 st century: Emerging questions, theoretical models, research designs and empirical findings. 
Social Development, 9, 115-125.

Brown, J. S., Collins, A., \& Duguid, P. (1989). Situated cognition and the culture of learning. Educational Researcher, 18, 32-42.

Carey, S. (1988). Reorganization of knowledge in the course of acquisition. Ontogeny, Phylogeny, and Historical Development, 2, 1.

Chen, D., \& Stroup, W. (1993). General system theory: Toward a conceptual framework for science and technology education for all. Journal of Science Education and Technology, 2, 447-459.

Chesapeake Bay Program. Bay Barometer: A Health and Restoration Assessment of the Chesapeake Bay and Watershed (2008). Retrieved from http://www.chesapeakebay.net/publications/title/bay_barometer_a_health_and_resto ration_assessment_of_the_chesapeake_ba

Chi, M. T. H. (2000). Misunderstanding emergent processes as causal. Annual Conference of the American Educational Research Association (AERA), New Orleans, LA.

Chi, M. T. H. (2005). Commonsense conceptions of emergent processes: Why some misconceptions are robust. Journal of the Learning Sciences, 14, 161-199.

Clark, D., Nelson, B., Sengupta, P., \& D’Angelo, C. (2009, October). Rethinking science learning through digital games and simulations: Genres, examples, and evidence. In Learning science: Computer games, simulations, and education workshop sponsored by the National Academy of Sciences, Washington, DC. 
Clark, R. E., \& Elen, J. (2006). When less is more: Research and theory insights about instruction for complex learning. Handling Complexity in Learning Environments: Theory and Research, 283-295.

Colella, V. S., Klopfer, E., \& Resnick, M. (2001). Adventures in modeling: Exploring complex, dynamic systems with StarLogo. Teachers College Press, Williston, VT.

Creswell, J. W. (2007). Educational research: Planning, conducting, and evaluating quantitative and qualitative research. Upper Saddle River, NJ: Prentice Hall

di Sessa, A.A., \& Sherin, B. L. (1998). What changes in conceptual change? International Journal of Science Education, 20(10), 1155-1191.

Feltovich, P. J., Coulson, R. L., \& Spiro, R. J. (2001, December). Learners'(mis) understanding of important and difficult concepts: A challenge to smart machines in education. In Smart machines in education (pp. 349-375). Boston, MA: The MIT Press.

Funke, J. (1991). Solving complex problems: Exploration and control of complex problems. In Sternberg, R, \& Frensch, P. (Eds.), Complex problem solving: Principles and mechanisms (pp. 185-222). Hillsdale, NJ: Lawrence Erlbaum.

Gredler, M. E. (1996). Educational games and simulations: A technology in search of a (research) paradigm. Handbook of Research for Educational Communications and Technology, 1, 521-540.

Gredler, M. E. (2004). Games and simulations and their relationships to learning. Handbook of Research on Educational Communications and Technology, 2, 571581. 
Hare, M., \& Deadman, P. (2004). Further towards a taxonomy of agent-based simulation models in environmental management. Mathematics and Computers in Simulation, $64,25-40$.

Ifenthaler, D. (2010). Relational, structural, and semantic analysis of graphical representations and concept maps. Educational Technology Research and Development, 58, 81-97.

Jacobson, M. J. (2008). A design framework for educational hypermedia systems: Theory, research, and learning emerging scientific conceptual perspectives. Educational Technology Research and Development, 56, 5-28.

Jacobson, M. J., \& Spiro, R. J. (1995). Hypertext learning environments, cognitive flexibility, and the transfer of complex knowledge: An empirical investigation. Journal of Educational Computing Research, 12, 301-333.

Jacobson, M. J., \& Wilensky, U. (2006). Complex systems in education: Scientific and educational importance and implications for the learning sciences. Journal of the Learning Sciences, 15, 11-34.

Johnson-Laird, P. N., Byrne, R. M. J., \& Schaeken, W. (1992). Propositional reasoning by model. Psychological Review, 99, 418-439.

Jonassen, D. H. (1997). Instructional design models for well-structured and III-structured problem-solving learning outcomes. Educational Technology Research and Development, 45, 65-94.

Jonassen, D. H. (2006). On the role of concepts in learning and instructional design. Educational Technology Research and Development, 54, 177-196. 
Jonassen, D., Strobel, J., \& Gottdenker, J. (2005). Model building for conceptual change. Interactive Learning Environments, 13,15-37.

Klopfer, E., Yoon, S., \& Perry, J. (2005). Using palm technology in participatory simulations of complex systems: A new take on ubiquitous and accessible mobile computing. Journal of Science Education and Technology, 14, 285-297.

Learmonth, G., Smith, D.E., Sherman, W.H., White, M.A., Plank, J. (2011). A Practical approach to the complex problem of environmental sustainability: The UVA Bay Game. The Innovation Journal: The Public Sector Innovation Journal 16 (1).

Guba, E. G., \& Lincoln, Y. S. (1985). Naturalistic inquiry (75). Newbury Park, CA: Sage Publications.

Liu, L., \& Hmelo-Silver, C. E. (2009). Promoting complex systems learning through the use of conceptual representations in hypermedia. Journal of Research in Science Teaching, 46, 1023-1040.

Meadows, D. H., \& Wright, D. (2008). Thinking in systems: A primer. White River Junction, VT: Chelsea Green Publishing.

Meagher, T. (2009). Looking inside a participant's mind: Can an analysis of participant concept maps measure changes in environmental literacy? Electronic Journal of Science Education, 13, 1-28.

Meir, E., Perry, J., Stal, D., Maruca, S., \& Klopfer, E. (2005). How effective are simulated molecular-level experiments for teaching diffusion and osmosis? Cell Biology Education, 4, 235-248.

Metz, K. E. (2008). Narrowing the gulf between the practices of science and the 
elementary school science classroom. Elementary School Journal, 109, 24.

National Research Council. (2011). Learning science through computer games and simulations. Washington, DC: The National Academies Press.

National Science Foundation. (2009). Transitions and tipping points in complex environmental systems. Washington, DC: National Science Foundation.

Novak, J. D. (1984). Application of advances in learning theory and philosophy of science to the improvement of chemistry teaching. Journal of Chemical Education, $61,607$.

Novak, J. D. (1990). Concept mapping: A useful tool for science education. Journal of Research in Science Teaching, 27, 937-949.

Novak, J. D., \& Cañas, A. J. (2008). The theory underlying concept maps and how to construct and use them. Florida Institute for Human and Machine Cognition Pensacola FL. Retrieved from http://cmap.ihmc.us/Publications/ResearchPapers/TheoryCmaps/TheoryUnderlyingC onceptMaps.htm

Ottino, J. M. (2004). Engineering complex systems. Nature, 427, 399.

Penner, D. E. (2000). Explaining systems: Investigating middle school participants' understanding of emergent phenomena. Journal of Research in Science Teaching, $37,784-806$.

Penner, D. E. (2001). Complexity, emergence, and synthetic models in science education. Designing for science, 177-208.

Pirnay-Dummer, P., Ifenthaler, D., \& Spector, J. M. (2010). Highly integrated model 
assessment technology and tools. Educational Technology Research and Development, 58, 3-18.

Purvis, M. (2010). UVA Bay Game Player Guide. UVA Bay Game documentation.

Resnick, M. (1996). Beyond the centralized mindset. Journal of the Learning Sciences, 5, $1-22$.

Resnick, M. (1997). Turtles, termites, and traffic jams: Explorations in massively parallel microworlds. Cambridge, MA: The MIT Press.

Resnick, M., \& Wilensky, U. (1993). Beyond the deterministic. Centralized Mindsets: New Thinking for New Sciences, Atlanta, GA: American Educational Research Association.

Resnick, M., \& Wilensky, U. (1998). Diving into complexity: Developing probabilistic decentralized thinking through role-playing activities. Journal of the Learning Sciences, 7, 153-172.

Richmond, B., \& Peterson, S. (2001). An introduction to systems thinking. High Performance Systems Incorporated. Retrieved from http://www.iseesystems.com/resources/Articles/STELLAIST\%28Ch1\%29.pdf

Rising Above the Gathering Storm Committee. (2010). Rising above the gathering storm, revisited: Rapidly approaching category 5. Washington, DC: National Academy Press.

Rousseau, D., \& van der Veen, A. M. (2005). The emergence of a shared identity: An agent-based computer simulation of idea diffusion. Journal of Conflict Resolution, $49,686$. 
Seel, N. M. (1999). Educational diagnosis of mental models: Assessment problems and technology-based solutions. Journal of Structural Learning and Intelligent Systems, $14,153-185$.

Seel, N. M. (2008). Empirical perspectives on memory and motivation. Handbook of Research on Educational Communications and Technology, 39-54.

Seel, N. M., Ifenthaler, D., \& Pirnay-Dummer, P. (2009). Mental models and problem solving: Technological solutions for measurement and assessment of the development of expertise. Model-Based Approaches to Learning: Using Systems Models and Simulations to Improve Understanding and Problem Solving in Complex Domains, 17-40. Rotterdam, The Netherlands: Sense Publishers.

Sengupta, P., \& Wilensky, U. (2009). Learning electricity with NIELS: Thinking with electrons and thinking in levels. International Journal of Computers for Mathematical Learning, 14, 21-50.

Shute, V. J., Jeong, A. C., Spector, J. M., Seel, N. M., \& Johnson, T. E. (2009). Modelbased methods for assessment, learning, and instruction: Innovative educational technology at Florida State University. Educational Media and Technology Yearbook, 61-79.

Spector, J. M. (2010, September). Assessing progress of learning in complex domains. $11^{\text {th }}$ International Conference on Education Research, New Educational Paradigm for Learning and Instruction, 1-13.

Spector, J. M., Christensen, D. L., Sioutine, A. V., \& McCormack, D. (2001). Models and simulations for learning in complex domains: Using causal loop diagrams for 
assessment and evaluation. Computers in Human Behavior, 17, 517-545.

Spiro, R. J., Feltovich, P. J., Jacobson, M. J., \& Coulson, R. L. (1992). Cognitive flexibility, constructivism, and hypertext: Random access instruction for advanced knowledge acquisition in ill-structured domains. Constructivism and the Technology of Instruction: A Conversation, 57-75.

Sterman, J. D. (1994). Learning in and about complex systems. System Dynamics Review, 10, 291-330.

Strauss, A., Corbin J. (1998). Basics of qualitative research. Thousands Oaks, CA: Sage Publications,

Taricani, E. M., \& Clariana, R. B. (2006). A technique for automatically scoring openended concept maps. Educational Technology Research and Development, 54, 6582.

Teddlie, C., \& Tashakkori, A. (2009). Foundations of mixed methods research: Integrating quantitative and qualitative approaches in the social and behavioral sciences Thousand Oaks, CA: Sage Publications, Inc.

Tobias, S., Fletcher, J., Dai, D. Y., \& Wind, A. P. (2011). Review of research on computer games. Computer Games and Instruction, 127.

Vogel, J. J., Vogel, D. S., Cannon-Bowers, J., Bowers, C. A., Muse, K., \& Wright, M. (2006). Computer gaming and interactive simulations for learning: A meta-analysis. Journal of Educational Computing Research, 34, 229-243.

Wang, F., \& Hannafin, M. J. (2005). Design-based research and technology-enhanced learning environments. Educational Technology Research and Development, 53(4), 
Watts, D. J., \& Strogatz, S. H. (1998). Collective dynamics of 'small-world'networks. Nature, 393, 440-442.

Wheeldon, J. P., \& Faubert, J. (2009). Framing experience: Concept maps, mind maps, and data collection in qualitative research. International Journal of Qualitative Methods, 8, 52-67.

Wilensky, U., \& Resnick, M. (1999). Thinking in levels: A dynamic systems approach to making sense of the world. Journal of Science Education and Technology, 8, 3-19.

Windschitl, M., Thompson, J., \& Braaten, M. (2008). Beyond the scientific method: Model-based inquiry as a new paradigm of preference for school science investigations. Science Education, 92, 941-967.

Yoon, S. A. (2008). An evolutionary approach to harnessing complex systems thinking in the science and technology classroom. International Journal of Science Education, $30,1-32$.

Young, M. F., Slota, S., Cutter, A. B., Jalette, G., Mullin, G., Lai, B., Simeoni, Z., Tran, M., Yukhymenko, M. (2012). Our princess is in another castle A review of trends in serious gaming for education. Review of Educational Research, 82, 61-89. 
Purvis, 2010

\section{Appendix A}

\section{Crop Farmer the uva bay game}

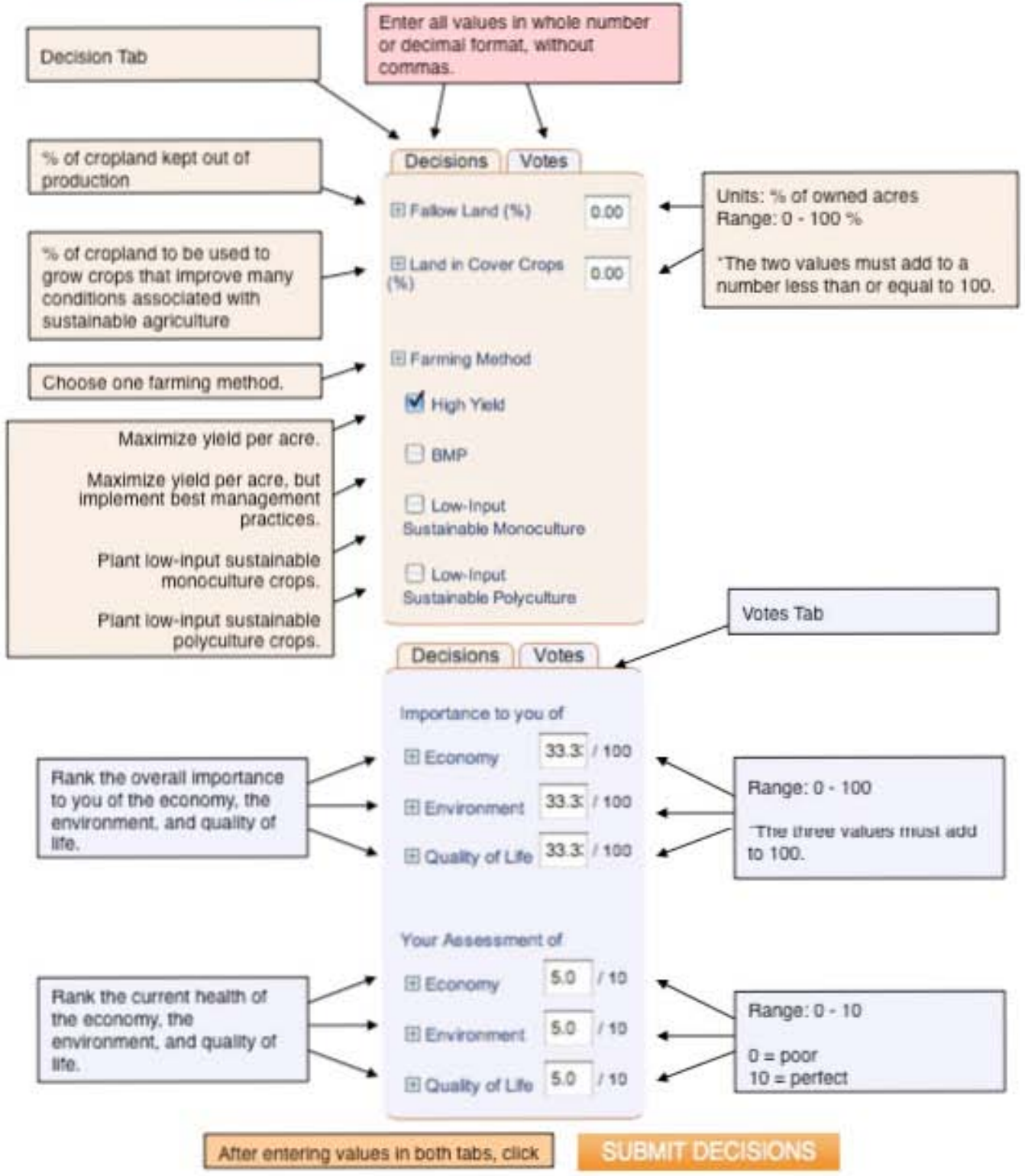


Purvis, 2010

\section{Appendix B}

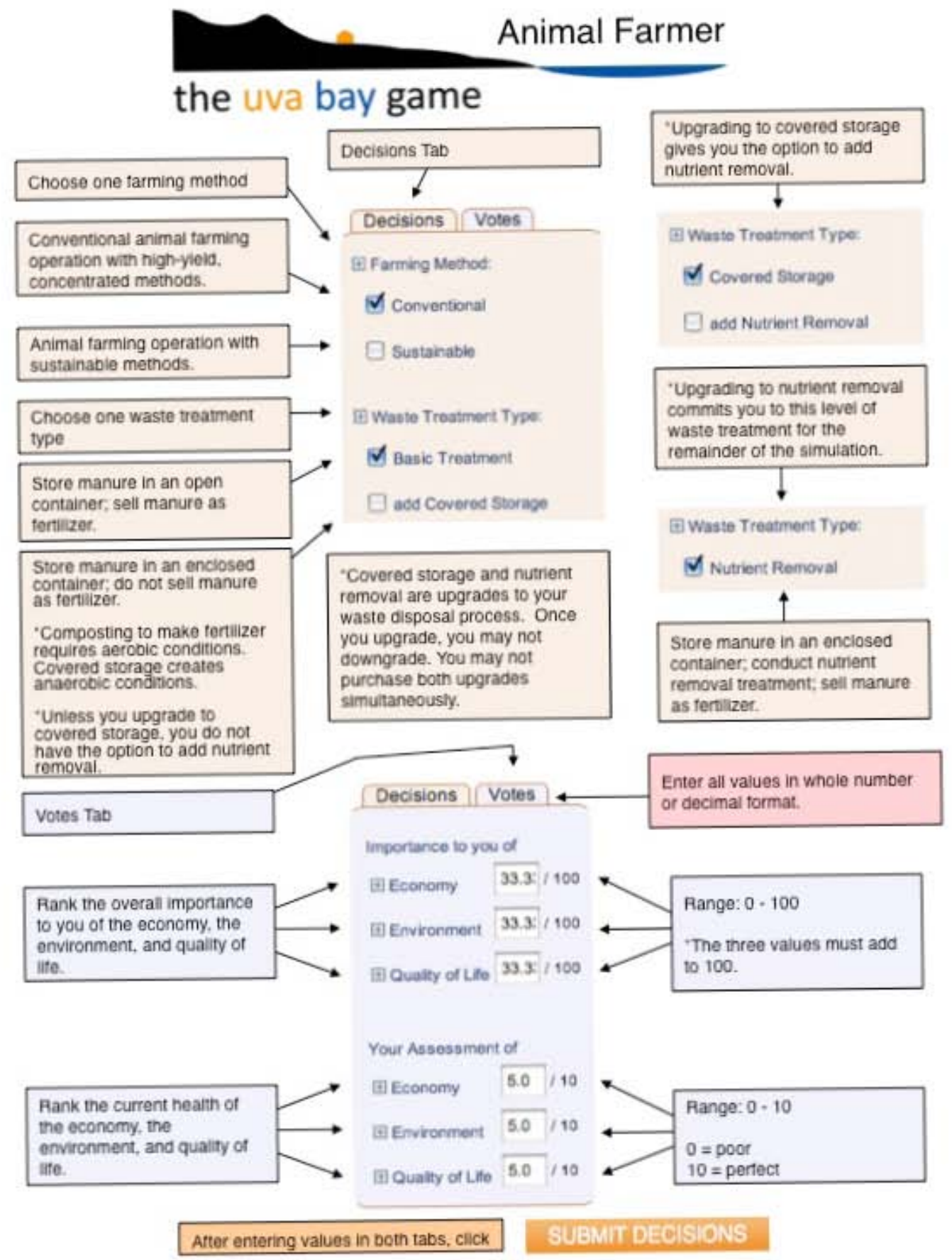


Purvis, 2010

\section{Appendix $\mathrm{C}$}

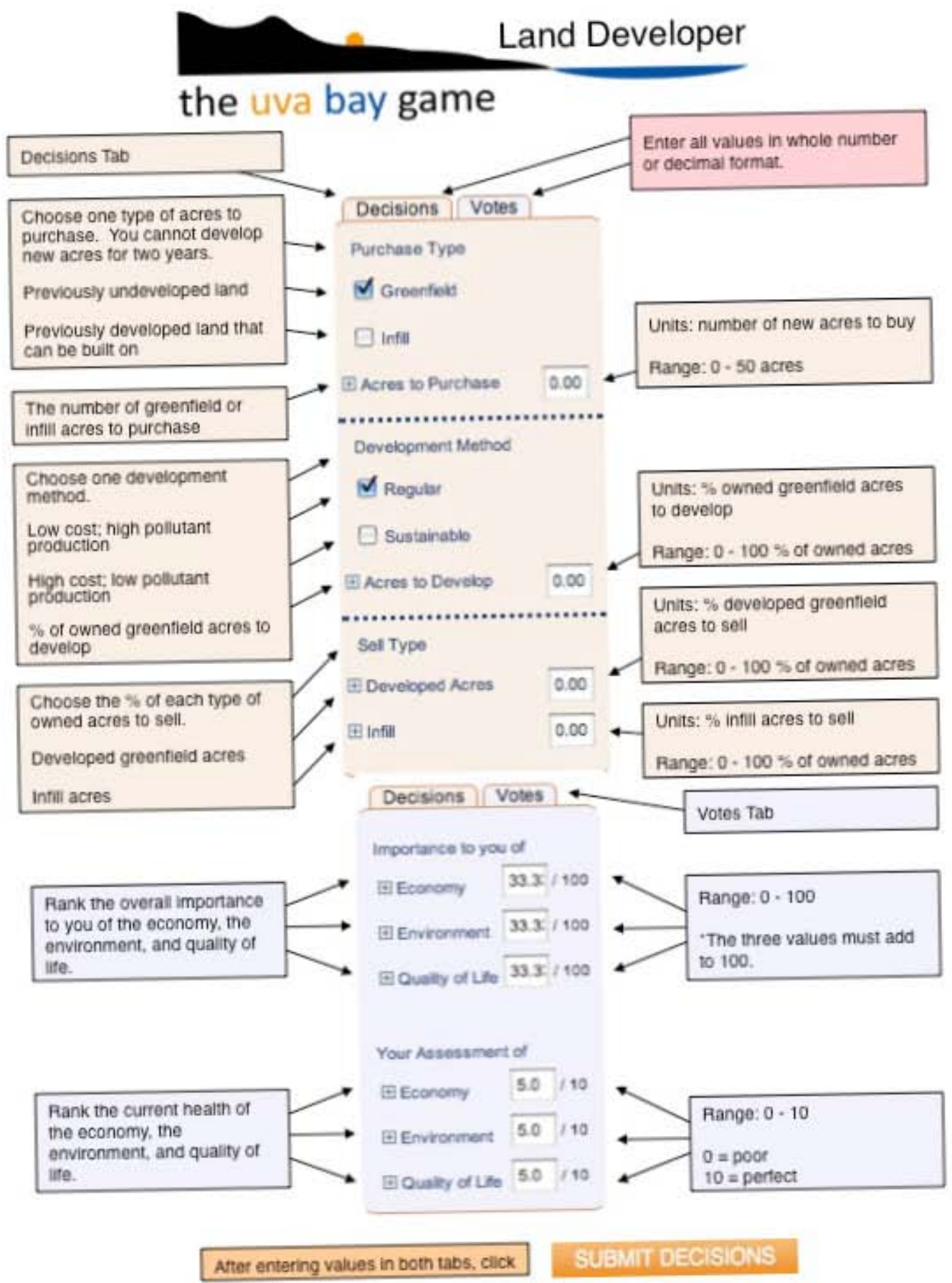


Purvis, 2010

\section{Appendix D}

\section{Waterman the uva bay game}
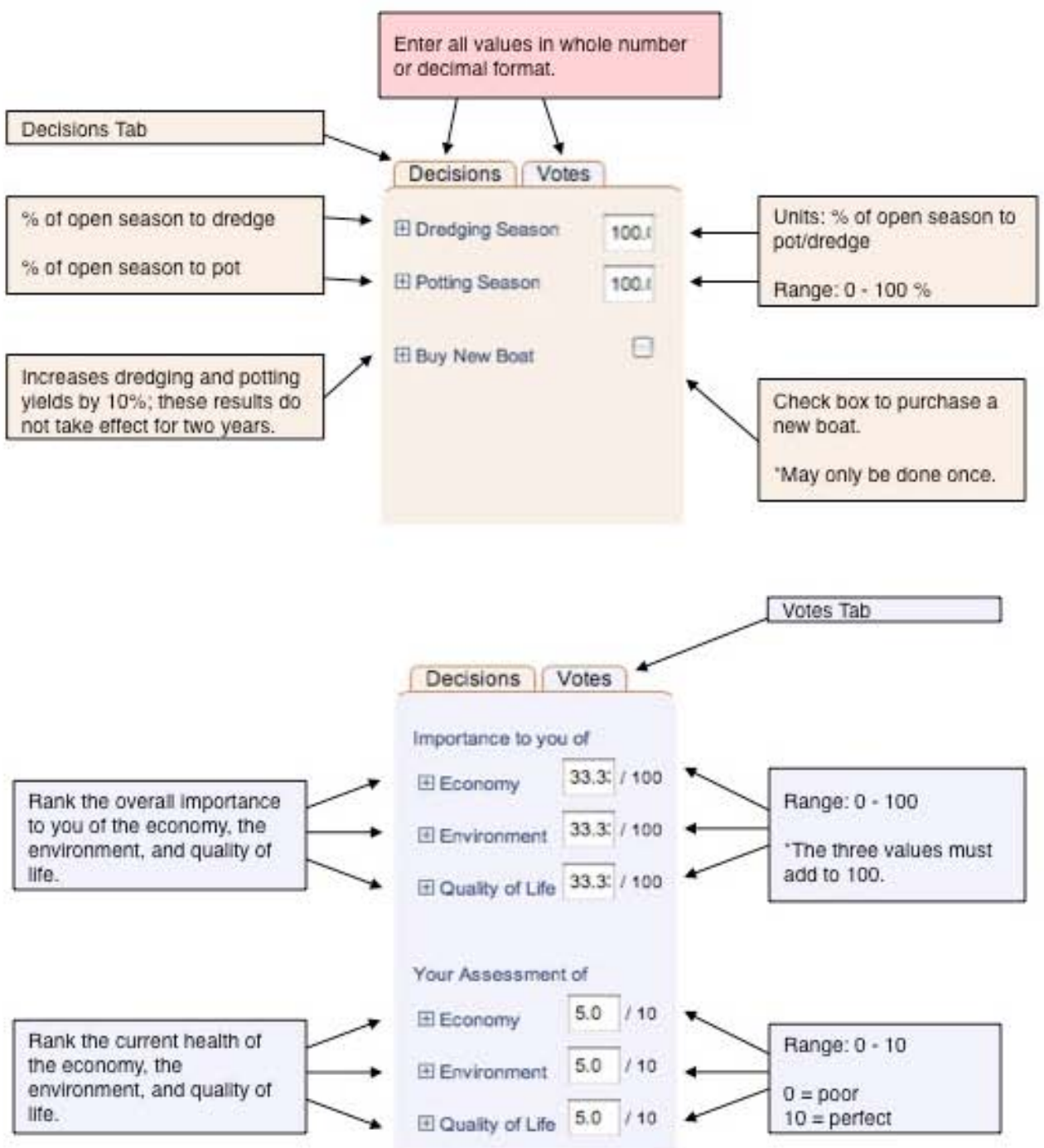

After entering values in both tabs, click SUBMII DECIBIONS 
Purvis, 2010

Appendix E
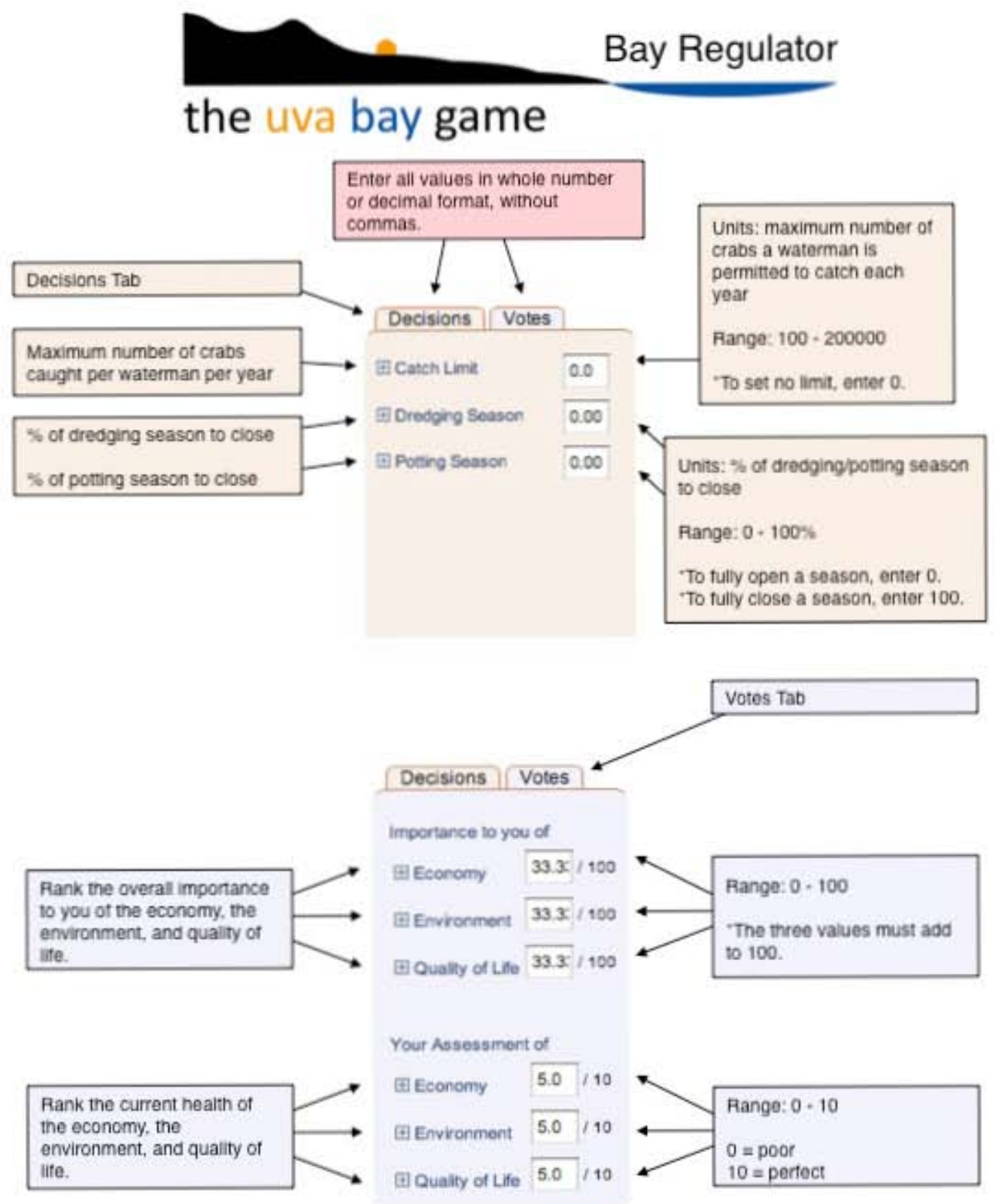
Purvis, 2010

\section{Appendix F}

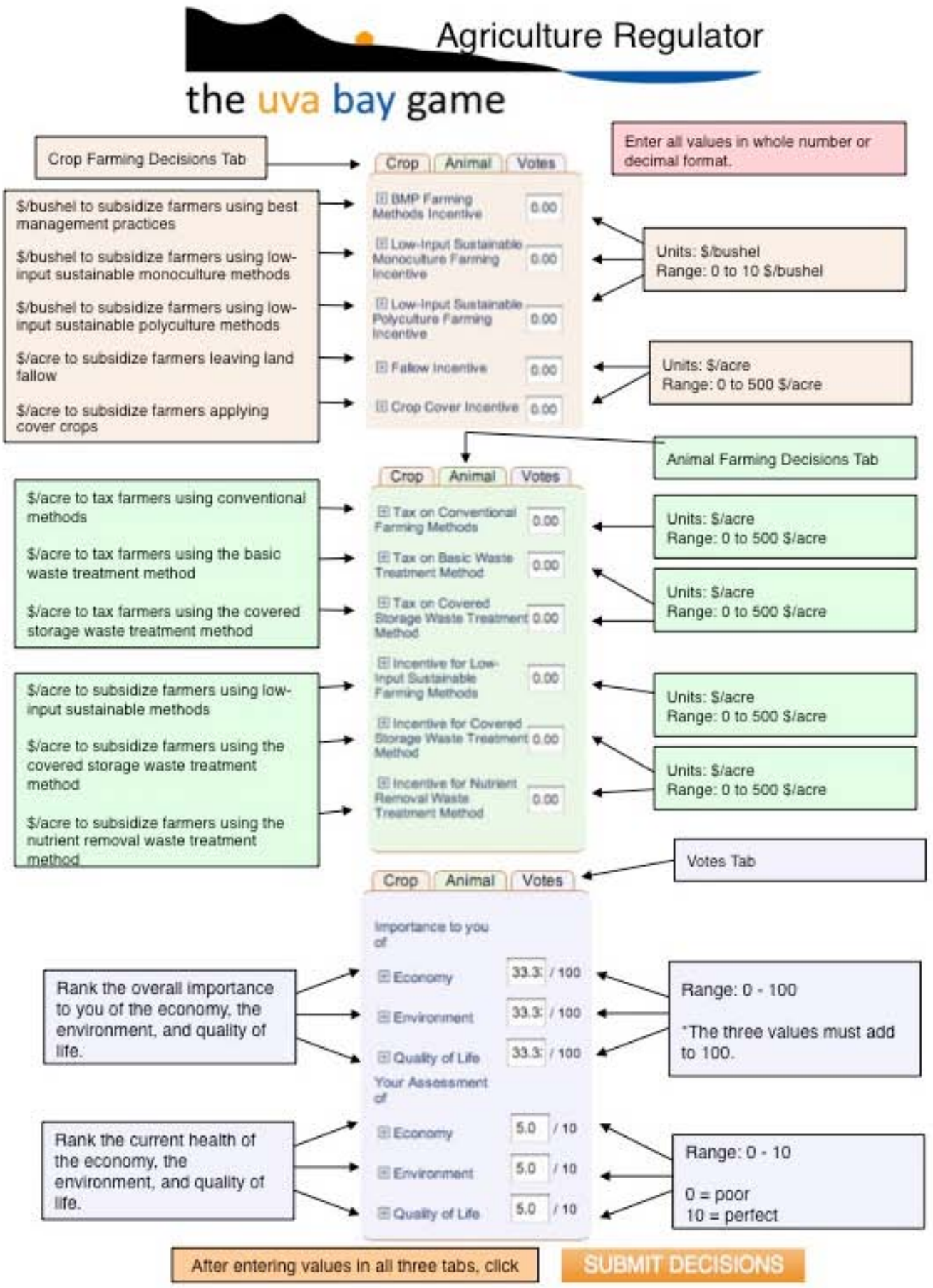


Purvis, 2010

\section{Appendix G}

\section{Land Use Regulator the uva bay game}
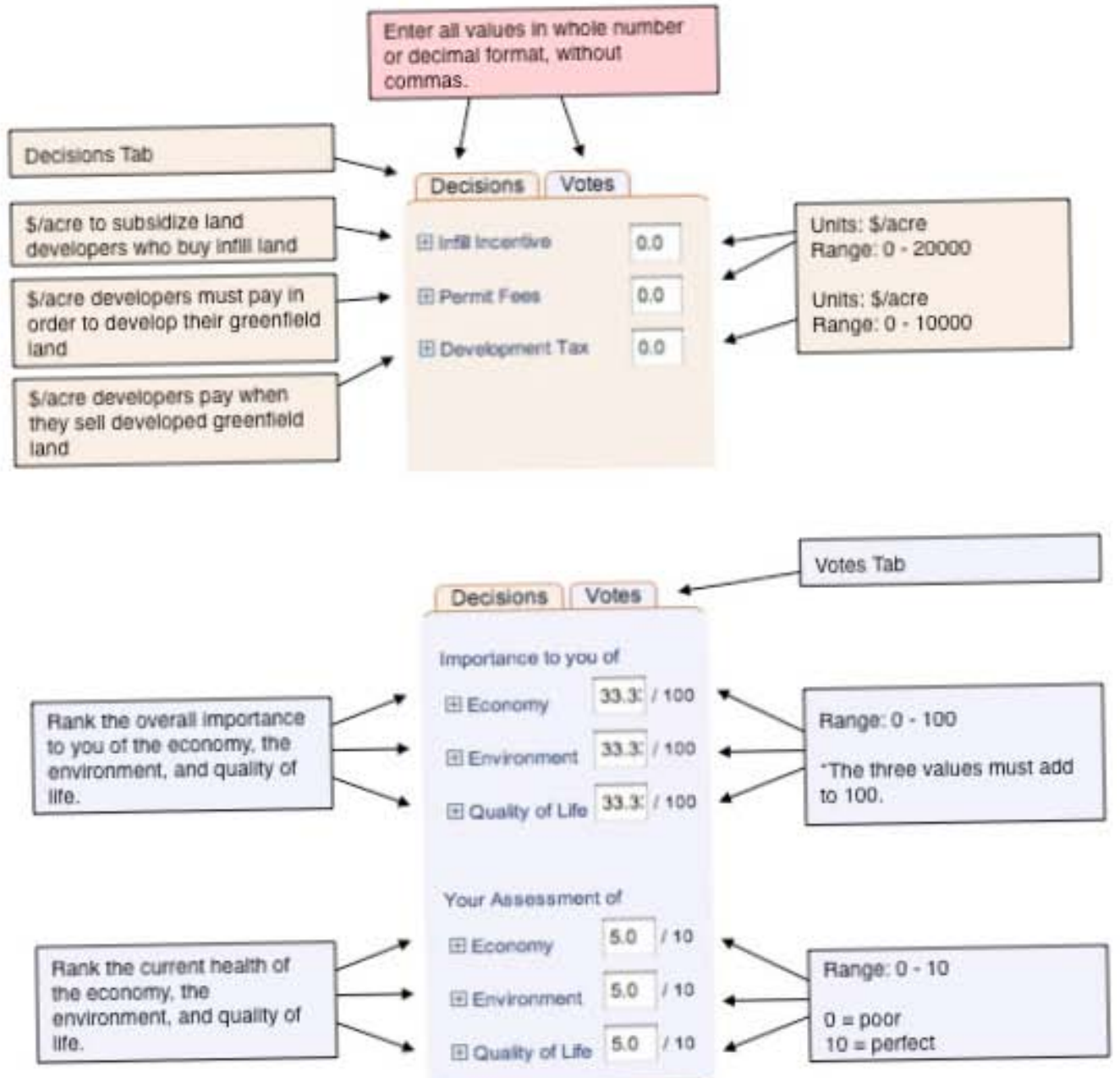


\section{Appendix $\mathrm{H}$}

Purvis, 2010

Wvisucamedivo

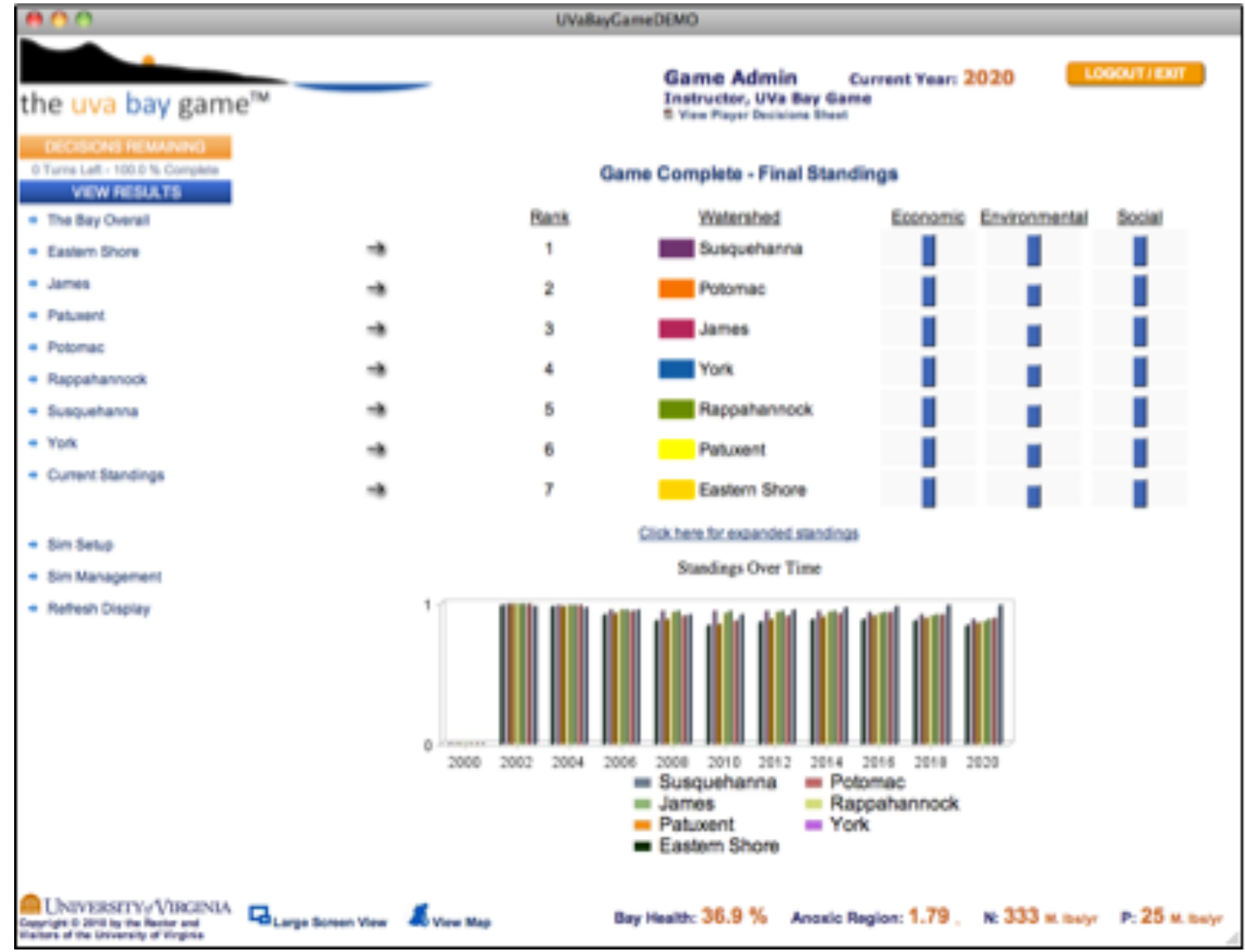




\section{Appendix I}

Please mark the appropriate sentence that describes your experience with the UVA Bay Game.

I have played the UVA Bay Game before. Number of times

I have NOT played the UVA Bay Game before.

Please respond to the following questions as completely as your current knowledge of the subject allows.

1. List the variables and concepts that you think are part of the Chesapeake Bay watershed system (You can list as many as you would like. Use additional space if needed).

2. Describe the relationship and interaction between these variables. Be specific. For example, if you state that $A$ influences $B$, indicate the direction and nature of the influence (i.e., A transforms B in this way, A increases/decreases B, etc.).

3. On a separate piece of paper, diagram (either free-hand or with a software program) the variables you described above demonstrating the relationships and interactions that influence the watershed. Whether you choose to draw your diagram free-hand or with the aid of a software program, a hardcopy of this diagram should be turned in to your instructor by Friday September 1, 2010.

Below are two examples of diagrams you can use as a guide, or you are free to diagram the system in the way that you feel best explains the variables and interactions you have described above. Please be sure that your diagram and labels are legible.

Example 1. 

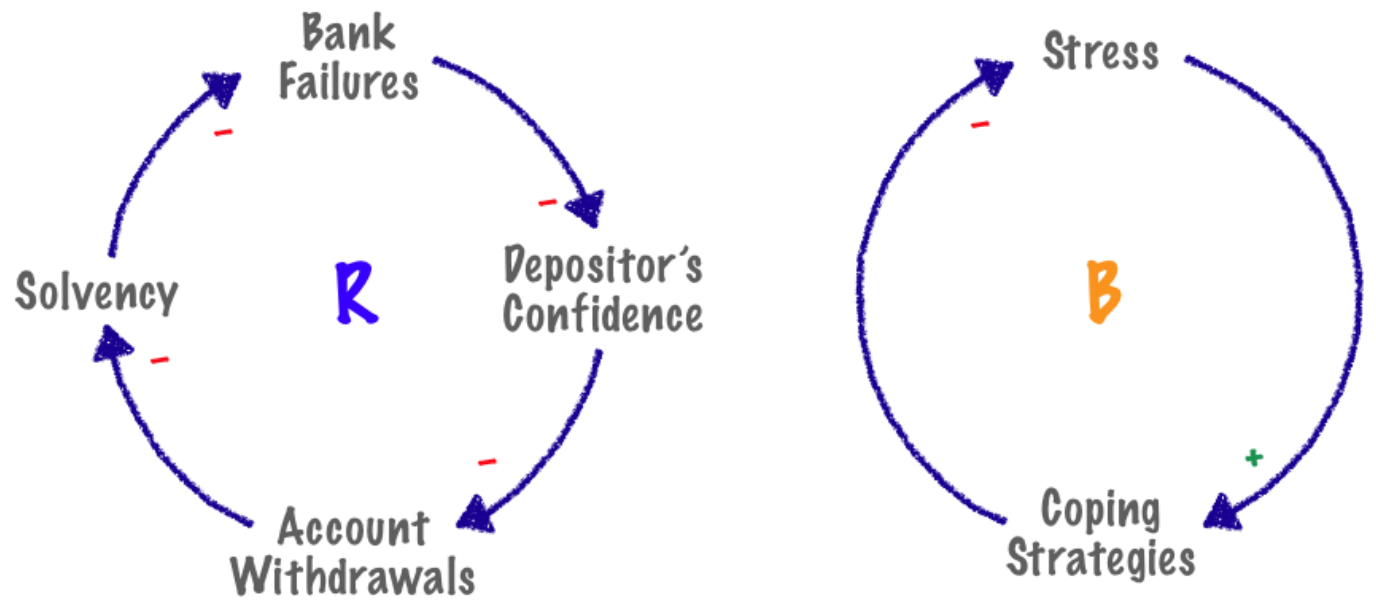

Example 2.

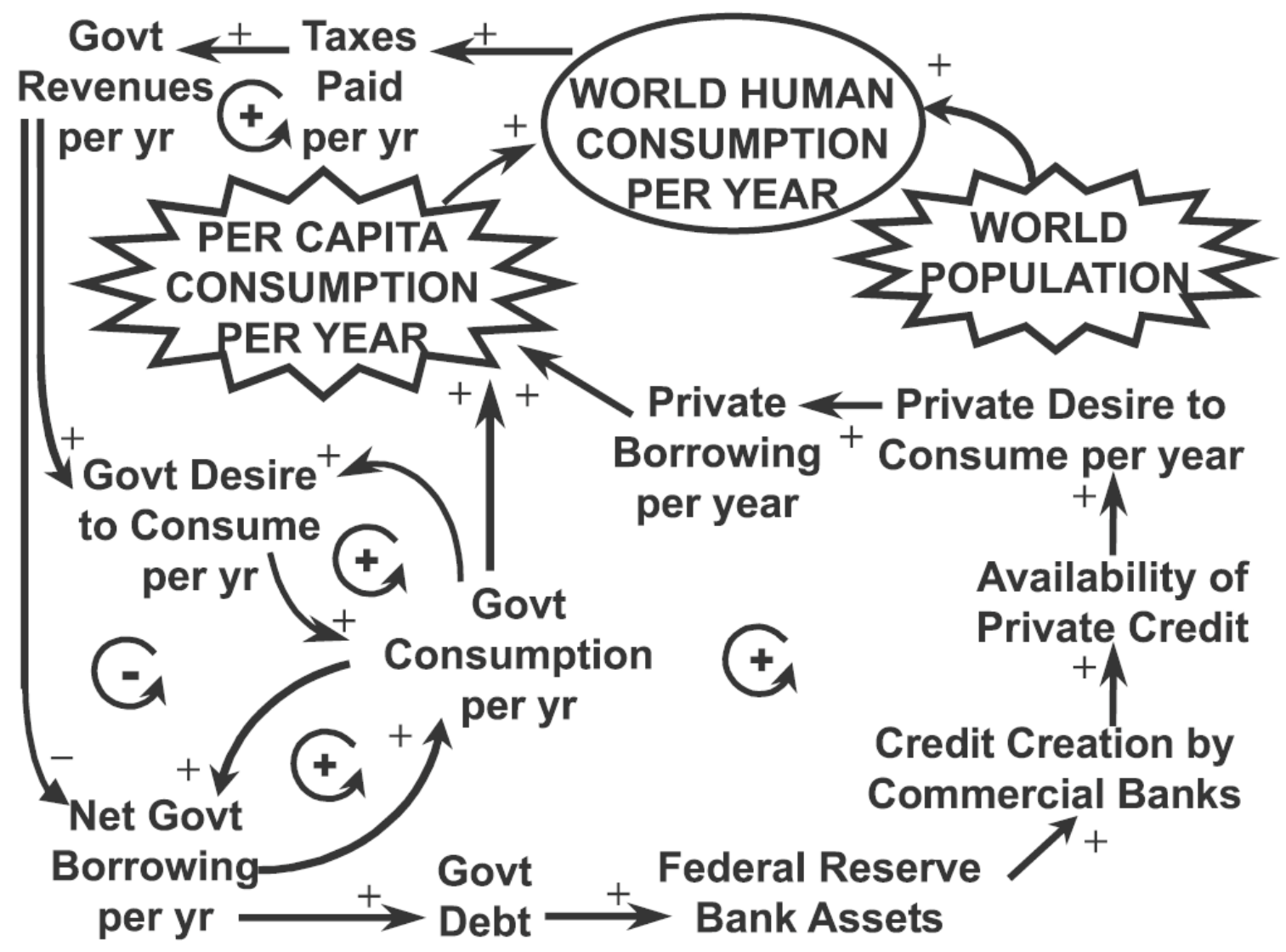




\section{Appendix J}

Assignment 3: Bay Game Follow up Questions

Assigned: Tuesday, October 19

Due: Tuesday, October 26

1. According to Meadows, elements, interconnections and a function or purpose are necessary components in systems. Describe the elements, connections and/or functions or purpose in the Chesapeake Bay watershed system. Diagram the system including these elements.

2. Describe how your diagram and understanding have changed since your first diagram of the Chesapeake Bay watershed system.

3. How do you think delay affects the efforts to improve the health of the Bay?

4. What was your perceived understanding of the goal/s of the game? Did you think the overall goal/s "fit" with your goals as a stakeholder and citizen? Describe how your understanding of the goal/s affected your actions within the game?

Optional:

We are improving the UVA Bay Game with each iteration and would like your feedback. Please share any thoughts you have on how the game could be better, what you liked, how it could be best used, and any other comments you have. 


\section{Appendix K}

\section{Assignment 2:}

\section{The Bay Game and the interface between natural and cultural ecosystems}

Assigned: Thursday, September 22, 2011

Due: Thursday, September 29, 2011 - post to your blog

1. According to Meadows, elements, interconnections and a function or purpose are necessary components in systems. Describe the elements, connections and functions or purpose in the Chesapeake Bay watershed system. The connections may take the form of feedback loops that either reinforce or stabilize certain relationships. Diagram the system including these components. Include environmental processes, the role of decision makers, and interactions that you see as critical to two basic indicators of Bay Health, the levels of nitrogen and phosphorus. You do not need to diagram the entire system, but may focus more on the dimensions of the systems that you experienced in the game.

2. In a short paragraph, describe an experience that you had during the game play that led to a new insight about the system or a deeper understanding of the processes at work.

3. The Bay Game includes a limited set of tools for the policy makers and other roles to change the dynamics of the model. Imagine and describe a real---world strategy to improve bay health through behavior change, market strategy, policy or player choice. Think about the systems leverage points from Meadows as suggestions for changing system behavior - you may either invent a strategy or describe how a similar strategy was used in another circumstance. How would your idea potentially affect the behavior of the economic and environmental models that the game is based on?

Optional:

We are improving the UVA Bay Game with each iteration and would like your feedback. Please share any thoughts you have on how the game could be better, what you liked, how it could be best used, and any other comments you have. 


\section{Appendix L}
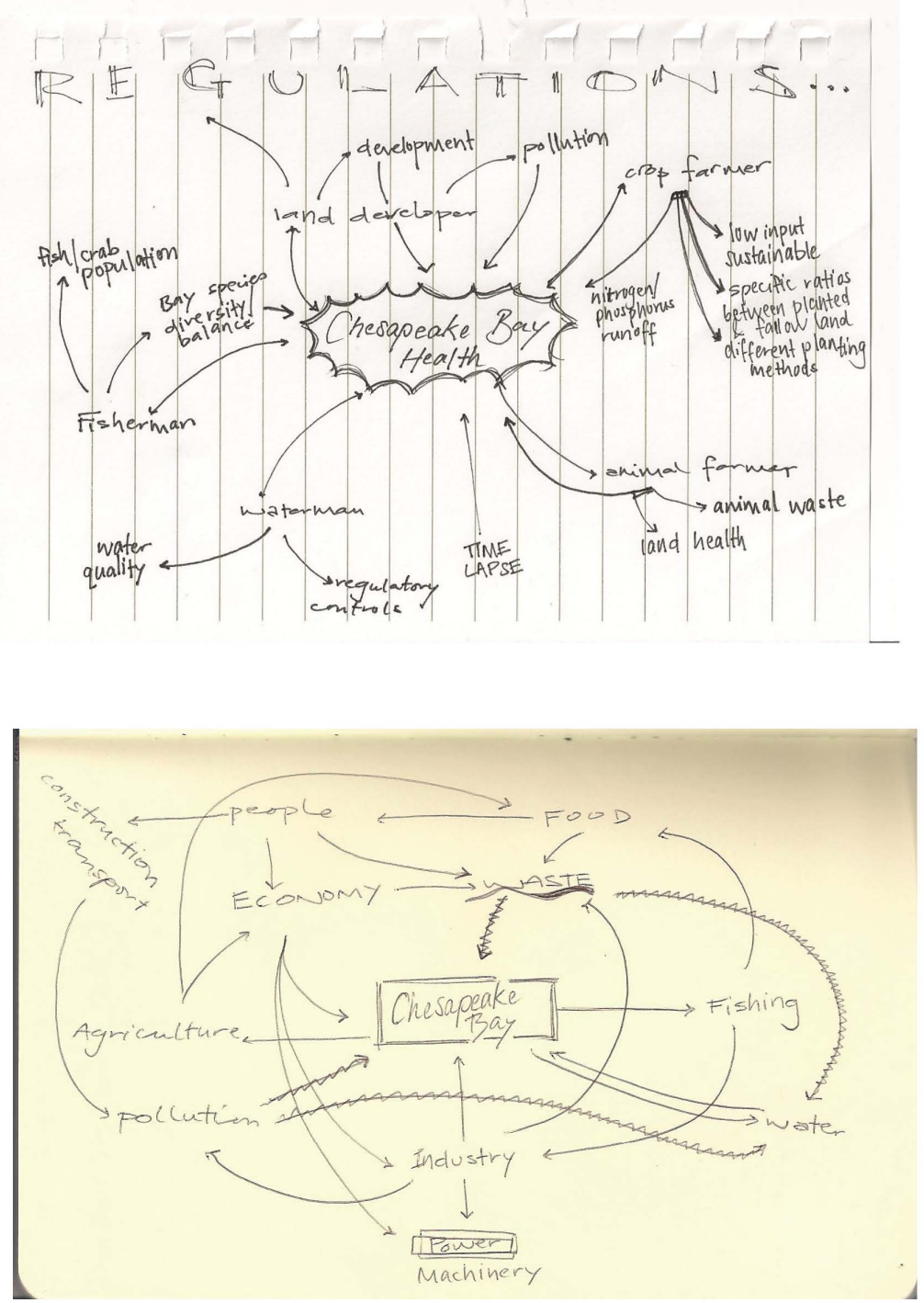

॥ \#1 (top) Better ॥ \#2 (bottom) Better ॥ Same 